\title{
New Capital Estimates for China
}

Data on physical capital are an indispensable part of economic growth and efficiency studies. In the case of China, fixed asset time series are usually derived either by aggregating gross fixed capital formation data ove r time, net of depreciation, or by correcting the limited official fixed asset data available. These procedures, to varying degrees, ignore that (i) gross fixed capital formation does not equal investment, (ii) investment does not equal the value of fixed assets newly created through investment, (iii) depreciation is an accounting measure that has no impact on changes in the production capacity of fixed assets, (iv) official fixed asset data, where available, incorporate significant revaluations in the 1990s, and (v) the variable "net fixed assets," frequently used in the literature, is an inappropriate measure of fixed assets for the purpose of growth or efficiency studies.

This paper derives economy-wide fixed asset values for 1954-2002, correcting for these shortcomings. It also uses the so far unexplored method of combining economy-wide depreciation data (in the income approach to the calculation of gross domestic product) with an economy- wide depreciation rate to directly yield economy-wide fixed assets. The fixed asset time series derived here are contrasted with each other as well as with those presented in the literature. The reliability of the different series is evaluated, leading to the recommendation of a specific choice of fixed asset time series.

$\underline{\text { Keywords }}$

Capital, fixed assets, investment, national income accounting, production function estimations, measurement of economic growth, Chinese statistics

JEL classification numbers

C80 Data Collection and Data Estimation Methodology, Computer Programs

D24 Production, Capital and Total Factor Productivity, Capacity

O47 Measurement of Economic Growth, Aggregate Productivity

P23 Factor and Product Markets, Industry Studies, Population

P24 National Income, Product, and Expenditure, Money, Inflation

Secondary: C43 Index Numbers and Aggregation

E10 General Aggregative Models

O40 Economic Growth and Aggregate Productivity

\author{
Carsten A. Holz \\ Social Science Division \\ Hong Kong University of Science \& Technology \\ Clear Water Bay \\ Kowloon \\ Hong Kong \\ E-mail: socholz@ust.hk \\ Tel/Fax: +852 2719-8557
}

18 March 2005 


\section{New Capital Estimates for China}

\section{Introduction}

Studies of economic growth in China inevitably rely on estimates of physical capital stock. Similarly, inquiries into sector- or ownership-specific efficiency levels and efficiency improvements require data on physical capital stock. Fixed asset time series are usually derived either by aggregating gross fixed capital formation data over time, net of depreciation, or by correcting the official fixed asset data which are available for some ownership groups in some sectors. Yet a closer examination of these procedures reveals major shortcomings.

For example, when economy-wide capital data in the literature are derived from gross fixed capital formation in the expenditure approach to the calculation of gross domestic product (GDP), these data are added up, net of depreciation, and deflated to constant prices. ${ }^{1}$ This ignores (i) that gross fixed capital formation does not equal investment, (ii) that investment does not equal the value of fixed assets newly created through investment (due to reasons ranging from waste to time lags), and (iii) that depreciation is an accounting measure that has no impact on changes in the production capacity of fixed assets. The margins of error due to these three shortcomings are on the order of approximately $-10 \%$ to $45 \%$ (overestimation of investment), 20\% (overestimation of effective investment), and 500\% (overestimation of decommissioned fixed assets by erroneously applying depreciation rates).

In sectoral analysis, of, for example, industry, where current-price cumulative fixed asset data are available for some ownership groups, the significant revaluations of the mid-1990s embedded in the fixed asset data are routinely ignored. This implies that the fixed asset data of the 1990s are price-adjusted twice, once in the official data themselves, and the second time by researchers through the procedures they have adopted to price-"correct" the official data. These studies, furthermore, use the for production function estimations inappropriate measure of "net fixed assets."

This paper focuses on economy-wide data. It starts by clarifying the meaning of fixed assets in Chinese statistics. It then presents two different approaches to the calculation of fixed assets. The first approach is based on the national income (and product) accounts (NIA). Economy-wide depreciation in the income approach to the calculation of GDP is combined with a depreciation rate to directly obtain (current-price) economy-wide fixed assets. The second approach follows the traditional method of accumulating investment over time, but uses formal equations to clarify the choice and derivation of a proper fixed asset measure, derives the necessary scrap rate, and adopts effective investment values; shortcomings in the literature are pointed out where relevant.

The outcome of these two approaches is a number of economy-wide capital series for China. The range of values across different series reflects the range of uncertainty involved in Chinese data. Nevertheless, some time series are more plausible than others and this paper offers a recommendation as to which time series to choose. In contrast to the fixed asset time series constructed here, those in the literature, apart from being conceptually flawed, tend to constitute extreme values. 


\section{Fixed asset definition}

The term "fixed assets" (guding zichan [heji]) in China's accounting system denotes the sum of (i) net fixed assets (guding zichan jingzhi), (ii) corrections to fixed assets (guding zichan qingli) due to, for example, sale, damage or the decommissioning of the fixed asset, (iii) fixed assets under construction (zaijian gongcheng), and (iv) unresolved net losses on fixed assets (dai chuli guding zichan jing sunshi). The first item in this list, net fixed assets, is by far the largest in size; it is itself the difference between fixed assets at their original value (guding zichan yuanzhi) and cumulative depreciation (leiji zhejiu). ${ }^{3}$

For growth studies, and thus, usually, production function estimations, neither "fixed assets" nor "net fixed assets" are appropriate because these are accounting artifacts. An accounting item such as "corrections to fixed assets," "fixed assets under construction," or "unresolved net losses on fixed assets" does not contribute to production. Net fixed assets attempt to approximate a hypothetical remaining sales value of the stock of fixed assets rather than the contribution of the fixed assets to production. For example, a machine that has already been written off completely and, thus, has a net fixed asset value of zero, may still be in use and contribute as much to production as a new machine of the same quality.

The proper measure of fixed assets in production function estimations is the original value of fixed assets, adjusted for price changes. Even a machine that is completely written off is included in the category "original value of fixed assets," at its purchasing price, as long as it is still in use. The fact that a machine in some account is listed at $10 \%$ of its original purchasing price does not imply that its contribution to production is only $10 \%$ of what it was when the machine was bought. Only once the machine is decommissioned is there an impact on production; the original value of fixed assets (and cumulative depreciation) then appropriately reduces by the original value of this particular machine. Accounting aspects, such as corrections to the value of fixed assets, fixed assets under construction, or unresolved net losses on fixed assets are all excluded from the original value of fixed assets, as they should be for a proper measure of physical capital in production function estimations. ${ }^{4}$

Viewed differently, output of a particular period is created by combining the inputs capital and labor (and perhaps other inputs). Labor is not adjusted for the remaining lifetime of the particular laborers employed in this period. Why should fixed assets be adjusted for the remaining (accounting) lifetime after this period ${ }^{5}$ There is no reason why they should. Just as the variable labor in production function estimations is a count of the laborers (or their hours worked) during the production period, the appropriate fixed asset measure is a count of the fixed assets used during the production period. This count is the original value of fixed assets, price-adjusted so that all fixed assets reflect a common price level. (The qualification "original" or "original value" is in the following omitted unless needed to contrast the original value of fixed assets with another measure of fixed assets.)

Two complications of (the original value of) fixed assets as a measure of capital are the following. First, the few data points on fixed assets that are available for specific enterprise groups in specific sectors of China's economy often reflect a total that consists of "productive" (shengchanyong) and "non-productive" fixed assets. Non-productive fixed assets comprise such items as staff housing. If the objective is to relate, for example, industrial output to industrial inputs, industrial fixed assets should be free of non-productive components. ${ }^{6}$ However, if the objective is to relate economy-wide output to economy- wide inputs, all fixed assets are relevant, including the "non-productive" fixed assets. For example, 
imputed rent on the non-productive fixed asset housing enters GDP, i.e., the output side, and thus should also enter the input side. The capital-output ratio of housing could be higher than that of machinery in industry, i.e., the amount of fixed assets needed to produce one unit of output could be higher in housing than in industry, but the mixing of very different production processes is a problem of all aggregate production functions. ${ }^{7}$

Second, the 1990s are marked by a series of revaluations. Rapid inflation in the late 1980s and mid-1990s meant that depreciation funds, based on the original value of fixed assets, became too low to replace obsolete fixed assets. In 1993, the government asked state-owned enterprises (SOEs) to revalue all fixed assets purchased before 1991 to market prices (and to raise their depreciation funds correspondingly); enterprises were allowed to spread the revaluation over several years if they could not afford to implement them immediately. Enterprises in other ownership forms were asked to follow suit in the following years. ${ }^{8}$ Companies which want to list on the stock market undergo a complete audit (and usually revaluations) prior to listing. As a result, for most of the 1990s (after 1992) the aggregate stock of fixed assets in a particular ownership group and/or sector reflects an unknown mix of fixed assets valued at original prices and of fixed assets valued at current market prices. In the construction of an economy-wide fixed asset time series (below), this is an issue that will have to be addressed. ${ }^{9}$

Economy-wide data on the value of fixed assets in China are not available. Fixed asset data covering some specific part of the economy are available for some years. ${ }^{10}$ These data help identify year-specific scrap rates which are then used in the derivation of the economywide fixed asset time series, and provide a double-check on constructed fixed asset series.

Fixed asset series in the following are derived via two approaches. In the first approach, absolute economy-wide depreciation data from the national income accounts (NIA) are divided by depreciation rates to directly obtain fixed asset values. In the second approach, effective investment is accumulated over time to form a fixed asset series, taking into consideration the fixed assets decommissioned annually.

\section{NIA approach to the calculation of fixed asset values}

In the income approach to the calculation of GDP, GDP is the sum of the four components labor remuneration, depreciation, net taxes on production, and operating surplus. These data are available for the reform period (the years since 1978). Dividing the economywide depreciation values by depreciation rates yields the economy-wide midyear (original value of) fixed assets. One immediate and possibly substantial shortcoming is that the resulting fixed asset values cover only those fixed assets which have not yet been fully depreciated. Those fixed asset values which have already been fully depreciated do not lead to any further depreciation and are thus not reflected in the economy-wide depreciation values. On the other hand, this straightforward calculation does yield the desirable measure of original value of fixed assets, even directly as a midyear value, just not covering all fixed assets; the coverage issue does not affect growth rates if it is constant over time. The simplicity of the procedure recommends its further exploration despite its shortcoming.

Depreciation in the NIA is defined sector by sector (similar to value-added in the production approach). In general, according to the National Bureau of Statistics (NBS, 1997, pp. 15f.), depreciation consists of actual and imputed depreciation. Imputed depreciation, 
such as for government organs, non-enterprise facilities and housing is based on "unified" (presumably meaning centrally determined) depreciation rates and unified original fixed asset values. It is acknowledged that, in principle, depreciation should be based on replacement values, but that this is not yet feasible for all fixed assets in China.

The first subsection below estimates economy-wide depreciation rates. The second subsection elaborates on the available NIA depreciation data. In the third subsection, depreciation values are divided by depreciation rates to obtain economy-wide fixed assets. The final subsection translates these into fixed asset values at constant year 2000 prices.

\section{Depreciation rates}

Economy-wide depreciation rates are not published. The following depreciation rates are available or can be calculated (Table 1). (i) Depreciation rates of budgetary SOEs and of budgetary SOEs in some economic sectors, such as industry, have been published for the years 1953-57, and 1960-92/93; in terms of fixed assets, budgetary SOEs account for approximately four-fifths of all SOEs. ${ }^{11}$ For budgetary SOEs in industry, depreciation rates can also be constructed from limited provincial data for 1991-1998 (in the second data column of the table, in parentheses). (ii) Actual depreciation rates of all industrial SOEs as well as of all directly reporting industrial enterprises (third and fifth data column in the table) can for some years be calculated from published depreciation data and fixed assets data. ${ }^{12}$ Provincial-level data, available for some provinces in provincial statistical yearbooks, allow the calculation of depreciation rates of industrial SOEs in years when nationwide data are not available (fourth data column in the table). (iii) An economy-wide value for five provinces based on end-year (rather than midyear) fixed assets can be calculated for 2000 (sixth data column).

An approximate economy-wide depreciation rate is constructed by observing the patterns between the different time series in Table 1 .

(1) Budgetary SOEs: the official depreciation rates for industry (second data column) are 0.1 to 0.5 percentage points higher than those for all SOEs (first data column).

(2) Budgetary vs. all industrial SOEs: the actual depreciation rates (depreciation divided by midyear original value of fixed assets) of all industrial SOEs are 0.6 to 0.9 percentage points lower than those for budgetary industrial SOEs; either the official depreciation rates are not implemented as stated, or the non-budgetary industrial SOEs have extremely low depreciation rates. For all industrial SOEs, the approximations based on those provinces for which depreciation and fixed asset data are available are likely to, given the 1991 and 2001 comparison data points, yield a reliable proxy for the national depreciation rates in years when those cannot be calculated.

(3) Industrial SOEs vs. directly reporting industrial enterprises: the actual depreciation rates of all directly reporting industrial enterprises (which include all industrial SOEs) are 0.35 to 0.47 percentage points higher than the actual ones of all industrial SOEs.

(4) The economy-wide depreciation rate of 2000, approximated based on only five provinces, is 0.44 percentage points higher than the approximated depreciation rate of all industrial SOEs, but is based on end-year rather than midyear original fixed assets, which means it is an under-estimate of the actual depreciation rate. ${ }^{13}$

The last pattern suggests that the economy-wide depreciation rate is likely to be above but close to the actual depreciation rate of all industrial SOEs. Constructing an approximate 
economy-wide depreciation rate for the reform period, this synthesized rate follows the actual depreciation rate of all industrial SOEs whenever these rates can be calculated (data columns three and four), with a very small increase (rounding up) in 2001-02, and slight smoothing in 1999 and 2000 to reach the more reliable 2001 value. ${ }^{14}$ In the years $1978-84$ when actual industrial SOE depreciation rates are not available, the reference rates are the official depreciation rates for budgetary SOEs and budgetary industrial SOEs (considering the patterns between these two series and all industrial SOEs in 1985-91). The approximate economy-wide depreciation rates are reported in the seventh data column of Table 1.

\section{From provincial-level to national depreciation data}

National data on the income approach to the calculation of GDP are not available. What are available are provincial data on income approach (gross) value-added ("provincial GDP") and the four individual components (labor remuneration, depreciation, net taxes on production, and operating surplus), for the years 1978-1995 in the compendium GDP 195295, and for the years 1993, 1994, and 1996-2003 in the Statistical Yearbook. For each province, the individual components add up to income approach value-added, and provincial income approach value-added usually equals provincial production approach value-added. ${ }^{15}$ Consequently, the sum across provinces of production approach value-added and income approach value-added are identical or near-identical (first two data columns in Table 2).

However, the sum of provincial value-added (production or income approach) since the mid-1990s is usually several percentage points higher than the national GDP figure published by the NBS. ${ }^{16}$ This is true for the national GDP figure both as first published by the NBS and for the revised GDP figure later published by the NBS. (Provincial value-added figures are not revised in the Statistical Yearbook; the provincial figures for 1978-1995 from GDP 195295 are likely to be once-and-for-all final figures.) The largest part of the discrepancy each year is typically located in the tertiary sector, and it is uncertain which values are more accurate, the provincial or the national ones. Since the NBS expects the economic census of 2004 to yield large upward revisions to national tertiary sector value-added, it could well be that the provincial data are more accurate than the national ones.

The implications for the calculations here is that depreciation obtained as the sum of depreciation across provinces may but need not be too large. Two alternative economy-wide depreciation values can be obtained. In a first step, the ratio of depreciation to income approach GDP, both measured as sum across provinces, is obtained. In a second step, this ratio is applied to national production approach GDP (which constitutes the official national GDP figure). This assumes that the share of depreciation in the sum of provincial valueadded (GDP) is a good proxy for the share of depreciation in (national) GDP. Two values of national production approach GDP are (i) GDP as first published, since the provincial data at least since 1996 are first published data, and (ii) revised GDP. The two resulting alternative depreciation values differ little (Table 2). Since the revised national GDP figure is preferable to the first published one, the second alternative depreciation value is also preferable; this assumes that the revisions affect all components of income approach GDP equally.

Economy-wide original values of fixed assets at current prices 
Economy-wide fixed asset values are obtained by dividing one of the three economy-wide depreciation values (sum across provinces, adjusted to national GDP data as originally published, adjusted to revised national GDP) by the depreciation rates. One choice of depreciation rates is the approximate series in Table 1. Alternatively, one could assume a constant depreciation rate of, say, $5 \%$, as frequently done in the literature. ${ }^{17}$ Table 3 reports the resulting time series of fixed assets.

\section{Economy-wide original values of fixed assets at year 2000 constant prices}

The economy-wide (original values of) fixed assets reported in Table 3 need to be adjusted for prices and decommissioned fixed assets. Current-year fixed assets equal previous-year fixed assets, plus newly increased fixed assets through investment, less the original value of those fixed assets that were decommissioned during the year. In order to obtain a constant price series of fixed assets, the values of newly increased fixed assets need to be deflated.

A deflator for investment in fixed assets is only available since 1991. For the years 1953 through 1995 an alternative deflator is the implicit deflator of gross fixed capital formation in the expenditure approach to the calculation of GDP in the national income accounts. The implicit deflator of gross fixed capital formation comes closer to the definition of investment in fixed assets than any other official price index or deflator and is therefore used for the years 1953 through 1990; in the overlapping years 1991 through 1995 the two deflators differ only marginally. ${ }^{18}$ (For the combined gross fixed capital formation deflator and investment in fixed asset price index (since 1991) see the last two columns of Table 1.)

One complication is that while the fixed assets in Table 3 are by construction midyear values, the deflator series reflects end-year values. One could attempt elaborate transformation of midyear into end-year values and back, but the accuracy of the underlying data and the unequal distribution of investment over the course of a year make further manipulations seem excessive. In the following, no attempt is made to bridge the time discrepancy between midyear fixed assets and end-year deflators.

A second complication is that the values of decommissioned fixed assets are unknown. One choice is to assume them to be zero. Table 4 reports the resulting midyear economy-wide fixed asset values at year 2000 constant prices (1978 value and annual increases are inflated/deflated to year 2000 prices). ${ }^{19}$ Four cases are included: depreciation values as sum of provincial data or based on revised national GDP, each combined with the approximate or constant $5 \%$ depreciation rates. ${ }^{20}$ These fixed asset series reflect the year 2000 purchasing price of all fixed assets currently in use and not yet fully depreciated (ignoring distortions due to revaluations examined below).

An alternative to assuming no decommissioning of fixed assets is to assume a $1 \%$ scrap rate applied to previous-year fixed asset values, a rate that will be argued below is plausible. The annual increase in fixed assets (to be deflated and added up to obtain fixed assets) is now obtained as the absolute difference between nominal current year fixed assets and nominal previous year fixed assets, where previous year fixed assets are multiplied by 0.99 . Table 4 also reports these results. The difference to the deflated data with a scrap rate of $0 \%$ even in the most recent years is only a few percentage points; average annual growth rates are slightly higher. The series are further examined below after alternative fixed asset series via 
the cumulative investment approach have been derived and the impact of revaluations in the 1990s has been examined.

\section{Cumulative investment approach to the calculation of the fixed asset values}

A second approach to calculating the economy-wide original values of fixed assets is to add up annual inve stment over time, net of the fixed assets decommissioned annually. Deriving fixed asset values through the cumulative investment approach requires (i) clarification of the relationships linking investment to fixed assets, (ii) a choice of the investment data to be used, and (iii) the development of an annual scrap rate to take into account decommissioned fixed assets. Once these three elements are in place, (iv) investment data on state-owned units (SOUs) and non-SOUs are, for reasons of data availability, accumulated separately and then added up; the results, depending on varying assumptions made to complete the calculations, are compared for the year 1992. In a final step, (v) the annual additions to fixed assets are inflated to year 2000 prices.

The comparison year 1992 is chosen for three reasons. First, for a few "benchmark" years SOU fixed asset values can alternatively be constructed from dispersed sectoral SOU fixed asset data; the 1992 value is likely to be more accurate than that of other years thanks to the 1993 tertiary sector census (covering 1991 and 1992). Second, as shown below, investment values in the early 1980s and before are likely to be incomplete, which makes an early 1980s comparison year inferior; the use of a later year, such as 1992, bypasses some of the data problems. Third, due to the unknown amount of revaluations that occurred starting in 1993, 1992 is the last year likely to yield accurate results without the need to introduce additional assumptions.

\section{Logical relationships between fixed asset variables, depreciation, and investment}

Six accounting identities, all in nominal terms, link fixed asset variables, depreciation, decommissioned fixed assets, and investment. The original value of fixed assets is in the equations abbreviated as "OFA" and the net value of fixed assets as "NFA."

The original value of fixed assets, less cumulative depreciation, equals net fixed assets:

$$
\mathrm{OFA}_{\mathrm{t}}-\text { cumulative depreciation }_{\mathrm{t}}=\mathrm{NFA}_{\mathrm{t}} \text {. }
$$

The identity is confirmed by the published official data on directly reporting industrial enterprises or SOEs, where occasionally data on all three variables are available. For each particular fixed asset at original value, an enterprise adds to its (cumulative) depreciation account each year until the particular fixed asset has been written off in full. Once it has been written off in full, no further depreciation is added for this particular fixed asset. ${ }^{21}$ The fixed asset may be in use, running at $100 \%$ of its capacity, for many more years, during all of which there is no further addition to the depreciation account.

Once the fixed asset is decommissioned, the depreciation account, i.e., cumulative depreciation, is written down by the original value of the fixed asset (or by the amount by which the particular fixed asset has been written off so far, with additional entries in other accounts depending on if the fixed asset is sold or discarded). The same applies to the 
original value of fixed assets. I.e., if a fully depreciated fixed asset is decommissioned, the two items on the left-hand side of the equation are each reduced by the same amount. ${ }^{22} \mathrm{Net}$ fixed assets, on the other hand, at this occasion remain unchanged. Net fixed assets is an accounting concept that solely considers a hypothetical remaining value of those fixed assets not yet fully written off. It measures neither the market value of fixed assets currently in use, nor the contribution of fixed assets currently in use to production (relevant for growth and efficiency studies).

The original value of fixed assets changes over time according to the identity

$$
\mathrm{OFA}_{\mathrm{t}}-\mathrm{OFA}_{\mathrm{t}-1}=\text { investment }_{\mathrm{t}}-\text { scrap value }_{\mathrm{t}}+\text { revaluation }_{\mathrm{t}},
$$

where investment refers to newly increased fixed assets through investment rather than to the published investment data (on which more below). The equation states that the current-period original value of fixed assets equals the previous period's original value of fixed assets, less the original value of decommissioned fixed assets ("scrap value") in this period, plus any increase in the value of fixed assets due to either investment or the revaluation of existing fixed assets. ${ }^{23}$

Equation (2) differs significantly from the literature. For example, Gary Jefferson et al. (2000), p. 808, define net investment (at current prices) as " $\mathrm{OPF}_{\mathrm{t}}-\mathrm{OPF}_{\mathrm{t}-1}+$ depreciation allowance," where OPF denotes the year-end value of productive fixed assets at original cost. $^{24}$ This is problematic in two respects. First, the depreciation allowance is an accounting item with no implication for the change in the value of OPF or for "net investment." The ir equation as it stands is logically incorrect. Second, Gary Jefferson et al. ignore revaluations. ${ }^{25}$ Since their study covers the years 1980 through 1996, in 4-year intervals, with data for the shareholding group only from 1993 through 1996, ignoring revaluations is likely to have significant implications for the results of their calculations in the last 4-year interval. ${ }^{26}$

It is unclear whether Gregory Chow and Kui-Wai Li (2002), Wang Yan and Yao Yudong (2003), Alwyn Young (2003), and Wu Yanrui (2004) regard the fixed asset values they derive as original or net fixed asset values. If the first, then they erroneously use the depreciation rate instead of the scrap rate, omit revaluations, and use an inappropriate investment measure of gross fixed capital formation or accumulation (on which more below).

Equation (2) can also be written as

$$
\mathrm{OFA}_{\mathrm{t}}-\left(1-\text { scrap rate }_{\mathrm{t}}\right) \mathrm{OFA}_{\mathrm{t}-1}=\text { investment }_{\mathrm{t}}+\text { revaluation }_{\mathrm{t}}
$$

if the scrap rate is defined as

$$
\text { scrap value } \text { t }_{\mathrm{t}}=\text { scrap }_{\text {rate }} * \mathrm{OFA}_{\mathrm{t}-1} \text {. }
$$

This specification of the scrap rate is arbitrary. It relates the original value of decommissioned fixed assets in a particular year to the previous-year original value of fixed assets. The original value of last period's fixed assets is the sum of a large number of fixed assets which have been purchased at different periods of time each at the then current price level. Each year some fixed assets are scrapped; some of these may be 50 years old, while others may only be 10 years old. Furthermore, the average lifetime of fixed assets may change over time. If one chooses as base the original value of fixed assets 40 years ago, the 
average scrap rate of SOUs (with as base $\mathrm{OFA}_{\mathrm{t}-40}$ ) on average, across years, tends towards unity. But with a 40-year lag, scrap rates can only be established for the 1990s. ${ }^{27}$

Third, the depreciation account, i.e., cumulative depreciation (abbreviated as "cum. depr.") changes according to the identity

$$
\text { Cum. depr.t }=\text { cum. depr.t-1 }+ \text { depreciation }_{\mathrm{t}}-\text { scrap value }_{\mathrm{t}}+\alpha * \text { revaluation }_{\mathrm{t}} \text {. }
$$

Current-year depreciation adds to cumulative depreciation, while the removal of a fixed assets means the depreciation account is reduced by the original value of the particular fixed asset (here labeled "scrap value"). ${ }^{28}$

If fixed assets are revalued, the original value of fixed assets changes by the full amount of revaluation. For example, if a fixed asset was originally purchased for 200 yuan RMB and is now revalued by 100 yuan RMB, it reaches a new "original" value of 300 yuan RMB. The depreciation account needs to change proportional to the value that has already been written off (therefore the factor $\alpha$ in the equation). If so far 50 yuan RMB have been written off, i.e., one quarter of the original purchasing price, the revaluation by 100 yuan RMB needs to be written off immediately by one quarter (i.e., $\alpha=0.25$ ). The depreciation account after the revaluation should (immediately) amount to $50+25$ yuan RMB for this particular fixed asset. ${ }^{29}$ The remainder of 75 yuan RMB enters the account of unresolved net losses (here: gains) on fixed assets.

Equations (1), (2), and (4) together imply equation (5), a transition identity for net fixed assets:

$$
\mathrm{NFA}_{\mathrm{t}}=\mathrm{NFA}_{\mathrm{t}-1}+\text { investment }_{\mathrm{t}}-\text { depreciation }_{\mathrm{t}}+(1-\alpha) * \text { revaluation }_{\mathrm{t}} .
$$

Equation (5) is not an independent equation and it is not needed below. In the accounting regulations, net fixed assets is defined only as the original value of fixed assets less cumulative depreciation (equation 1). However, equation (5) has found its (mistaken) use in the literature (where, furthermore, the revaluation term is ignored throughout). As argued above, net fixed assets is not an appropriate measure of fixed asset values for production function estimations; it is an accounting artifact that does not reflect the contribution of fixed assets to production.

Chen Kuan et al. (1988) and Gary Jefferson et al. (1992) set current-year "fixed assets at net value" equal to the sum of previous-year fixed assets at net value plus investment, less depreciation and less the book value of assets decommissioned. This is incorrect in that the decommissioning of fixed assets does not affect net fixed assets as long as the fixed asset has been fully written off by the time of decommissioning. Net fixed assets cons titute an accounting value of fixed assets that is net of depreciation; once a fixed asset has been fully depreciated, that fixed asset does not exist in the "net fixed asset" category any longer. ${ }^{30}$ The first authors subsequently regard decommissioned assets as small in value and ignore them; the second set these values equal to zero since they do not have the data. Gary Jefferson et al. (1996) correctly omit scrap values from the equation but then obtain investment values using equation (2) where they erroneously omit the scrap value term (and revaluation) on the righthand side. 
It is unclear whether Gregory Chow and Kui-Wai Li (2002), Wang Yan and Yao Yudong (2003), Alwyn Young (2003), and Wu Yanrui (2004) regard the fixed asset values they derive as original or net fixed asset values. If the latter, then depreciation is calculated incorrectly in that it is obtained by applying depreciation rates to net fixed assets rather than to the original value of fixed assets. This implies that the official linear depreciation is no longer linear, that already fully depreciated fixed assets continue to be depreciated forever, and that the "depreciation rates" used have no relationship to the actual depreciation rates in China. The accounting rules are unambiguous: the original value of a particular fixed asset is depreciated annually by a fixed amount until the fixed asset is fully depreciated; depreciation enters the cumulative depreciation account. Net fixed assets equal the original value of fixed assets less cumulative depreciation (equation 1). Thus, this literature not only uses the wrong fixed asset measure but also calculates it wrongly.

Every year, depreciation is incurred either on the average annual original value of fixed assets, or, for simplicity, on the end-year original value of fixed assets:

$$
\begin{aligned}
& \text { Depreciation }_{\mathrm{t}}=\text { depreciation rate }_{\mathrm{t}} *\left(\mathrm{OFA}_{\mathrm{t}}+\mathrm{OFA}_{\mathrm{t}-1}\right) / 2 \text { or } \\
& \text { Depreciation }_{\mathrm{t}}=\text { depreciation rate }_{\mathrm{t}} * \mathrm{OFA}_{\mathrm{t}} .
\end{aligned}
$$

The accounting regulations, for example for industry, require linear depreciation based on government-determined depreciation periods. ${ }^{31}$ Depreciation periods as of 1992 range from 4 years (computers) to 55 years (dams with electricity generation). For an individual fixed asset, equation (6') is used to calculate depreciation; the annual depreciation rate is one divided by the government-determined depreciation period. Depreciation is accumulated on a monthly basis, where the monthly depreciation rate is one-twelfth the annual depreciation rate. When the depreciation period has ended but the fixed asset is still in use, the original value of fixed assets in equation (6') remains unchanged; the equation continues to hold since the depreciation rate for this particular fixed asset then is zero.

An aggregate depreciation rate can de facto only be obtained as a residual of equation (6) (or $\left(6^{\prime}\right)$ ). It is unclear how the available official depreciation rates have been derived; to be accurate they need to have been obtained as residuals in this equation. Equation (6) (or (6')) is used here to obtain depreciation values, assuming that the depreciation rates are accurate.

Equation (6), using midyear fixed asset values, promises to yield more accurate depreciation values than equation (6') which uses end-year fixed asset values. Monthly investment data show that, consistently over the years, approximately two-thirds or more of all investment occurs in the second half of the year, and approximately two-fifths to one-half in the last quarter of the year. This implies that the most appropriate average annual value weighs previous year end-year fixed asset values with a factor of 2, compared to current-year end-year fixed asset values with a factor of 1 . For simplicity, and following that part of the literature which makes the effort to obtain average annual values, the arithmetic mean of previous and current year end-year values are used here ("midyear" values).

Lacking economy-wide fixed asset values - the purpose of this paper is to construct them-equations (1) through (4) and (6) are in the following used to obtain two scrap rate series from data available for only subsets of the economy. In a second step, economy-wide fixed asset values are obtained by combining these (limited-coverage) scrap rates with the available economy-wide investment data and assumptions about initial fixed asset values 
(equation 2). Since investment data are needed for the derivation of one of the two scrap rates (as well as, obviously, for the final derivation of economy-wide fixed assets), investment data are discussed next.

\section{Choice of investment data}

The proper investment measure in equations (2) and (5) is the newly increased value of fixed assets through investment (xinzeng guding zichan), in the following labeled "effective investment." The use of the measure investment is incorrect because not all investment expenditures lead to increases in fixed assets. This could be due to a number of reasons, including waste or time lags between when money is being spent and when the completed fixed assets are ready for use. Official statistics explicitly provide investment and effective investment data, as well as the (presumably residual) "transfer rates," i.e., the share of annual investment that turns into effective investment of that year.

One complication of both the investment and the corresponding effective investment data is that these data are unlikely to cover all investment across the economy. First, the data coverage changed over time. For example, investment by certain ownership groups has to be of a particular size before it is included in the statistics; this size criterion was raised in 1997. Or, prior to 1999, urban private and individualowned non-real-estate investment are not included in the statistics. Second, some types of investment appear to be excluded from the statistics until today. For example, non-real-estate investment of a value below 500,000 yuan $\mathrm{RMB}$ is not included in the statistics except if by state-owned units, rural collective-owned enterprises, or individuals. Investment data of the early reform period and pre-reform period may have an even more limited coverage than the recent data and their explanations suggest. ${ }^{32}$

An alternative is to use gross fixed capital formation in the expenditure approach to the calculation of GDP, available since 1952. In as far as expenditure approach GDP closely approximates production approach GDP and production approach GDP is a comprehensive measure of economy-wide production activities, gross fixed capital formation could be a rather comprehensive measure of investment. However, the definitions of gross fixed capital formation and investment do not perfectly match. According to the GDP Manual (2001), pp. 92-5, 106f., gross fixed capital formation in the expenditure approach to the calculation of GDP comprises (i) "total society investment in fixed assets" (this is economy- wide investment), (ii) value-added created in the sale of real estate, (iii) fixed assets created in the prospecting for mineral resources (kuangcang kantan), calculated as costs incurred in the prospecting for mineral resources times $75 \%$, and (iv) fixed assets created in the improvement of land (unless already included in total investment of society), less three items. The three items to be subtracted are (a) the purchase of old structures (jianzhuwu), old equipment (shebei), and land, (b) other items in "other costs" (qita feiyong) which do not constitute fixed asset investment, and (c) investment in afforestation, unless these numbers are very small and not easy to obtain, in which case they can be ignored. ${ }^{33}$

Data on economy-wide investment ("total society investment in fixed assets") are available since 1980. Figure 1 shows that in 1980 gross fixed capital formation exceeded economy-wide investment by $44.69 \%$. This difference diminished rapidly in the following years and by 1986 gross fixed capital formation was approximately equal to economy-wide investment. In order to make a conclusive comparison, one would need data on the other 
items in gross fixed capital formation besides economy-wide investment; a priori, relative to economy-wide investment, they are unlikely to be large.

Does this imply that official investment data underestimate actual investment in the years prior to 1986, and similarly for effective investment? If the gross fixed capital formation data are wrong on the scale the 1980 data suggest, this would question the official expenditure approach GDP value, and, because that value is highly similar to that for production approach GDP data, the official Chinese GDP data. ${ }^{34}$ However, gross fixed capital formation data through the mid-1980s may not be what they seem. These data were constructed retrospectively by manipulating data from the Material Product System to fit into the newly adopted System of National Accounts (with the variable gross fixed capital formation). Lacking clear definitions of these early data, the possibility cannot be ruled out that early gross fixed capital formation might include some inventory investment or consumption. I.e., Figure 1 can be interpreted as evidence of underestimated investment or of overestimated gross fixed capital formation, or of both.

In the literature, Wang Yan and Yao Yudong (2003), Alwyn Young (2003), and presumably Wu Yanrui (2004) use gross fixed capital formation as a proxy for investment. They seem to be unaware of the other items included in gross fixed capital formation and ignore the fact that not all investment expenditures translate into effective investment. Gregory Chow and Kui-Wai Li (2002) use gross capital formation (including inventories) since 1978 and a similar measure limited to the five material production sectors prior to $1978 . .^{35}$

Data on economy-wide effective investment are available for the years 1981 through 2002. Separate data on effective investment of SOUs are available for the years 1981 through 2003; this allows the derivation of effective investment of non-SOUs in the years 1981 through 2002 as difference of the two series.

For the years prior to 1981, SOU effective investment can be reliably estimated from two exhaustive components of SOU investment, for the significantly larger of which effective investment data are also directly available, and the latter's annual transfer rates can then be applied to the smaller investment component. ${ }^{36}$ Table 5 reports the available and estimated SOU effective investment data. A first-year (1953) original value of fixed assets is obtained using the perpetual investment method. ${ }^{37}$

Lacking investment and effective investment data for non-SOUs in the years prior to 1981, effective investment data for non-SOUs are estimated using four different methods. The first three methods rely on backward estimation of non-SOU effective investment values from a reform period value. All three methods rely on non-SOU effective investment data of 1986 or 1986-2000 and thus bypass the possibly underreported investment values of the early 1980s to obtain values for the years prior to 1986.

The first method consists of regressing the ratio of non-SOU to SOU effective investment in the years 1986 through 2000 on a constant and time (year). ${ }^{38}$ The trend line is rather stable over time and when extended to the years prior to 1986 yields positive ratios back to 1967 . Inserting the values on effective investment of SOUs for the years 1967 through 1986, nonSOU effective investment follows. ${ }^{39}$ 
The second method relies on the average annual real growth rate of non-SOU effective investment during the period 1986 through 2000. Applying this real growth rate subsequently to the value of 1986 and then of earlier years allows the backward creation of a time series of non-SOU effective investment. The 1953 value is replaced by the sum of all previous years up through 1953, obtained via the perpetual investment method. ${ }^{40}$

The third method starts with the 1986 value of non-SOU effective investment and extends it back in time to 1949 based on the real growth rate of non-SOE industrial gross output value. ${ }^{41}$ Underlying this method are the assumptions that the average capitaloutput ratio of non-SOUs is constant over time, and that output of non-industrial non-SOUs grows at the same rate over time as that of industrial non-SOUs. ${ }^{42}$ The advantage over the previous two methods is that historical growth rates rather than average future (post-1985) growth rates are used. $^{43}$

The fourth method obtains non-SOU investment for the years prior to 1986 as the difference of economy-wide gross fixed capital formation and SOU investment. These pre1986 non-SOU investment values are turned into effective investment using an estimated non-SOU transfer rate. ${ }^{44}$ Table 5 reports the non-SOU effective investment values following the four different methods as well as the transfer rates.

\section{SOE and SOU scrap rates}

Economy-wide scrap rates could be estimated if economy-wide original values of fixed assets and investment data were available, but they are not. Therefore, scrap rates are estimated for subsets of the whole economy where the necessary data to do so are available.

One way to calculate scrap values is to make use of depreciation rates. With cumulative depreciation from equation (1) and depreciation from equation (6), scrap values follow in equation (4); scrap rates are obtained by inserting the scrap value in equation (3). Solving the four equations for the "depreciation-based" scrap rate (and the unknown revaluation term) yields

$$
\begin{aligned}
& \text { scrap rate }_{t}-\left(\alpha * \text { revaluation }_{t} / \mathrm{OFA}_{\mathrm{t}-1}\right)= \\
& \left(\mathrm{OFA}_{\mathrm{t}-1}-\mathrm{OFA}_{\mathrm{t}}+\mathrm{NFA}_{\mathrm{t}}-\mathrm{NFA}_{\mathrm{t}-1}+\left(\text { depr. } \text { rate }_{t} *\left(\mathrm{OFA}_{\mathrm{t}}+\mathrm{OFA}_{\mathrm{t}-1}\right) / 2\right)\right) / \mathrm{OFA}_{\mathrm{t}-1} .
\end{aligned}
$$

The three time series original values of fixed assets, net fixed assets, and depreciation rates are available with values of all three series simultaneously for budgetary SOEs and all industrial SOEs, for the years 1953-98/ 1953-2003; for SOUs they can be approximated for 1953-98.

A second way to calculate scrap rates is to make use of effective investment values. These, together with the original values of fixed assets, immediately yield scrap rates in equation (2'). Solving equation (2') for the "investment-based" scrap rate (and the unknown revaluation term) yields

$$
\text { scrap rate }_{t}-\left(\text { revaluation }_{t} / \mathrm{OFA}_{\mathrm{t}-1}\right)=\left(\text { investment }_{t}+\mathrm{OFA}_{\mathrm{t}-1}-\mathrm{OFA}_{\mathrm{t}}\right) / \mathrm{OFA}_{\mathrm{t}-1} \text {. }
$$


Effective investment data are available or can be constructed for industrial SOEs for all years in the period 1953-2003 except 1966-74, and for SOUs are available for all years.

The ideal scrap rate comes as close to covering the whole economy as possible. But only on industrial SOEs is the set of necessary data available for the whole reform period (except effective investment data for 1966-74). Comparing the three depreciation-based scrap rates in the overlapping years for which more than one time series is available reveals them to move closely in step; the same is true, separately, for the two investment-based scrap rates. ${ }^{45}$ Two complete scrap rate series to be retained and examined in the following are (i) a depreciationbased one which consists of the values of budgetary SOEs in 1952-92 and of those of industrial SOEs in 1993-03, and (ii) an investment-based combined scrap rate series which consists of the values of SOUs in 1966-74, and of those of industrial SOEs otherwise (1953$65,1975-2003) .{ }^{46}$ Both series exhibit a severe statistical break in 1998 in that the coverage of fixed asset values in 1998 changes from SOEs to "SOEs and state-controlled enterprises," while the investment data continue to cover SOEs (only). The depreciation-based scrap rate series continues in 1999 with consistent data for the new enterprise coverage, while the investment-based scrap rate series in 1998 and all years thereafter reflects an inconsistent combination of investment and fixed asset data (implying underestimation of the scrap rate).

Table 5 reports the two scrap rate series. The scrap rates throughout are rather low, with the depreciation-based scrap rate around zero and 1\%, and the investment-based scrap rate covering a wide range of values, often negative ones. Equation (8) clarifies the meaning of a negative investment-based scrap rate: assuming that the original values of fixed asset series are correct (which is plausible for these subsets), a negative scrap rate implies a positive revaluation and/or underestimation of actual investment by official investment data. In the case of depreciation-based scrap rates, equation (7), the likely culprits for (the very few) negative scrap rates are either revaluation or poor depreciation rate data. Because no data on revaluations are available, the scrap rates in equations (7) and (8) capture revaluations; the scrap rate is calculated here as the right-hand side terms of the identities.

Since 1993, both scrap rates suggest large positive revaluations in 1994 and 1995, and the investment-based scrap rate also in 1993. Prior to 1993, the revaluation variable in equations (7) and (8) should be zero. In the case of the investment-based scrap rates, with frequent negative values, this suggests that the official investment and effective investment data are too small. ${ }^{47}$ The NBS is unlikely to be able to obtain data on truly all investment in SOUs or industrial SOEs across the country. The underestimate may be even worse in the case of nonSOUs, where data supposedly cover tens of millions of enterprises. ${ }^{48}$

The conclusion of these considerations is that if fixed asset data are available, the most appropriate scrap rates are the depreciation-based ones. This implies that authors who erroneously calculate net investment using depreciation rather than scrap value s (such as Gary Jefferson et al., 2000) obtain net investment values which are too large: the typical depreciation rates assumed in the literature are $5 \%$ or more compared to the scrap rates of around $1 \% .{ }^{49}$ With net investment values deflated in order to create a capital series in constant prices, the result is a capital series that at times of positive inflation is too small (excessively deflated).

On the other hand, if fixed asset data are not available but are to be constructed using data on effective investment, the most appropriate scrap rates are the investment-based ones because, given the way they have been derived, they incorporate an adjustment factor for 
underestimated official effective investment (and revaluations). ${ }^{50}$ Since the task of this paper is to construct economy-wide fixed asset values, the investment-based scrap rates are likely to be more appropriate here than the depreciation-based ones.

Both series come with the same two caveats. The first is the statistical break in 1998 which renders the depreciation-based scrap rate of 1998 (only) and the investment-based scrap rates of 1998 and the years thereafter meaningless.

The second caveat is that both series are affected by the revaluations (albeit to different degrees, compare equations 7 and 8), in ways that makes their use in the construction of fixed assets after 1992 undesirable. The objective of the official revaluations is to obtain an "original value" of fixed assets at current prices. ${ }^{51}$ What causes a problem in the calculations here is that the revaluations in the years 1993 and after are of an unknown amount and therefore by necessity captured in the scrap rates. This matters in the derivation of a nominal economy-wide fixed asset series after 1992 in that the use of these scrap rates causes a discretionary jump whenever revaluations happen. It also matters in the derivation of a constant price economy- wide fixed asset series after 1992 in that the constant price procedure itself values each year's newly increased fixed assets (and base year fixed assets) at constant prices; but after 1992 the use of these scrap rates (for purposes here, wrongly) inflates the newly increased fixed assets beyond scrap values by the unknown amount of revaluations. ${ }^{52}$ In other words, after 1992 the scrap rates correct the effective investment (or fixed asset) data in the creation of an economy-wide (nominal or real) fixed asset series not only for decommissioned fixed assets, as intended, but also, and for the purpose of creating a consistent economy-wide fixed asset series, wrongly so, for revaluations. After 1992, the two scrap rate series derived here should not be used in the derivation of economy-wide fixed asset series.

The solution for the years after 1992, adopted here, is the following. First, by 2003 revaluations are likely to be small, occurring if at all only in the process of changes to the organizational form of individual enterprises. The depreciation-based scrap rate of 2003, thus, is likely to be accurate. ${ }^{53}$ Connecting the reliable 1992 and reliable 2003 depreciation-based scrap rates through linear interpolation yields alternative depreciation-based scrap rates for 1993-2003 (also reported in Table 5). ${ }^{54}$ Second, by 2003 the official investment data should be highly complete, which implies that the investment- and the depreciation-based scrap rates should be near-identical. Consequently, the 2003 investment-based scrap rate is assumed to be identical to the depreciation-based scrap rate. ${ }^{55}$ Investment-based scrap rates for the years 1993 through 2002 then are obtained through linear interpolation between the 1992 investment-based scrap rate and the adopted 2003 depreciation-based scrap rate.

The literature that constructs net fixed asset series via increases in official fixed assets ignores the revaluations of the mid-1990s. The result is the overestimation of net fixed assets in later years. ${ }^{56}$ This is apart from the fact that depreciation in the construction of the net fixed asset series is calculated wrongly throughout the literature and that net fixed assets are not an appropriate fixed asset measure for production function estimations to begin with.

\section{Fixed asset values in 1992}

All components are now in place to derive fixed asset values for SOUs and non-SOUs via cumulative investment. The components are: SOU or non-SOU effective investment data 
from official sources for 1981-2003 and constructed for the years prior to 1980 (Table 5), two time series of scrap rates (Table 5), and the deflator (Table 1). Equation (2') specifies how to derive the fixed asset values of each year.

Table 6 in line "B" reports six SOU fixed asset values for 1992 based on three scrap rate scenarios times two valuation scenarios. The three scrap rates are the two derived scrap rate series and a scrap rate of zero; the two valuations are at original purchasing prices ("nominal") and inflated to 1992 values. Application of a scrap rate implies that a particular year's nominal fixed asset value equals the previous year's nominal fixed asset value times "one minus the scrap rate," plus effective investment in the current year. Deflating or (inflating) to constant price values implies, in a second step, the application of the deflator to each year's increase in the value of nominal fixed assets and then the accumulation of these annual "real" increases. The first year's value of fixed assets (1953) is deflated in full using the 1953 deflator value. ${ }^{57}$

The nominal values range from 2483.093b yuan RMB in the case of the depreciationbased scrap rate to $2736.093 \mathrm{~b}$ yuan RMB in the case of a scrap rate of zero and $2876.617 \mathrm{~b}$ yuan RMB in the case of the investment-based scrap rate; the last value exceeds the first by $15.85 \%$. With real values (in year 1992 prices), the maximum difference is $15.22 \%$. The values using investment-based scrap rates are the highest (because investment-based scrap rates are often negative, compensating for underreported investment); the values using depreciation-based scrap rates are the lowest.

An alternative to the cumulative investment approach is to sum up dispersed fixed asset values available for SOUs in different sectors of the economy. The nominal $1992 \mathrm{SOU}$ benchmark value thus derived, of 3076.845 b yuan RMB (reported in line A of Table 6), is $6.96 \%$ larger than the highest nominal value obtained via the cumulative investment method, the one in the case of investment-based scrap rates. ${ }^{58}$ The small size of the discrepancy either justifies the use of investment-based scrap rates in the cumulative approach or validates the benchmark value. No matter which conclusion one prefers, the cumulative investment approach (or some variation of it) is still necessary to derive nominal fixed asset values for other years (and all non-SOU values), as well as real fixed asset values for all years.

Lines C. 1 through C. 3 of Table 6 report the non-SOU fixed asset values based on cumulative effective investment. The underlying effective investment data prior to 1986 are derived following the first three methods as explained above: C. 1 uses the trend of the ratio of non-SOU to SOU effective investment in 1986-2000, C.2 the average annual real growth rate of non-SOU effective investment in 1986-2000, and C.3 (in part a.) the real growth rates of non-SOU industrial gross output value. Line E reports the non-SOU fixed asset value when effective investment is derived using the fourth method, with non-SOU investment as difference of economy-wide and SOU investment; economy-wide fixed asset values are also reported, in line D. ${ }^{59}$

An alternative, fifth procedure to obtain a non-SOU fixed asset value for 1992 only is to directly subtract the 1992 value of SOU original fixed assets (line A or B) from the 1992 economy-wide value of fixed assets (D); the resulting non-SOU fixed asset values are in lines F.1 or F.2 depending on whether the SOU value is the 1992 benchmark figure (A) or the cumulative SOU value (B). 
The results across the five methods differ (Table 6). Taking the case of nominal values with investment-based scrap rates, the five methods yield values from $1533.473 \mathrm{~b}$ yuan RMB to 2085.004b yuan RMB. The range, thus, is approximately one-third of the lowest value. The first three methods yield values towards the lower end of the range of values, the fourth and fifth method towards the higher end. Switching to values in 1992 prices does not change this pattern, nor does a switch to depreciation-based scrap rates. ${ }^{60}$

The close match of the SOU fixed asset benchmark value (line A) with the fixed asset value of SOUs derived from cumulative effective investment with investment-based scrap rates (B) suggests that SOU effective investment data cannot be far off, if at all. Among the investment data, those of SOUs are probably the best; if any units report regularly and reliably on their investment and newly increased fixed assets, it is the SOUs which by their very nature are part of the reporting system and whose investment in 1992 required government approval. But if the effective investment values of SOUs were of good quality, most burden of any underestimate of total investment prior to 1986 would be carried by nonSOUs. The first three methods used here to calculate non-SOU fixed asset values all bypass the question of how accurate non-SOU investment data of 1980-1985 and earlier years are by starting the regressive calculations from the presumably reliable 1986 effective investment value. ${ }^{61}$ In other words, by construction, the first three methods for calculating non-SOU fixed assets are unlikely to underestimate non-SOU investment. Yet the fourth and fifth methods, starting with gross fixed capital formation values, still yield higher values, even when investme nt-based scrap rates are used. This questions the gross fixed capital formation values used extensively in the literature perhaps more than it does the effective investment data combined with investment-based scrap rates.

Of the first three methods, the third one appears superior in that it does not rely on taking trends or growth rates established in the period 1986-2000 to the earlier years, but uses historical year-specific growth rates of a related variable to establish the effective investment values of earlier years. Its 1992 value is between those of the other two methods. The fourth method, which obtains annual non-SOU investment as the difference between economy-wide values - prior to 1986 gross fixed capital formation - and SOU values, is best when used with depreciation-based scrap rates. This is the case because gross fixed capital formation, at least in 1980-85 when comparison values are available, is significantly larger than economy-wide investment; the use of investment-based scrap rates, which compensate for any underreported investment, would then inflate non-SOU investment a second time. If gross fixed capital formation were indeed a good approximation of economy-wide investment, which is questionable, the resulting nominal 1992 fixed asset value using depreciation-based scrap rates is $1799.999 \mathrm{~b}$ yuan RMB (line E, Table 6). This value is eleven percent higher than the 1617.597b yuan RMB using the third method to obtain non-SOU fixed assets (investmentbased scrap rate, line C.3 in Table 6).

\section{Economy-wide fixed asset values (in constant year 2000 prices)}

Without an unambiguous procedure to obtain fixed asset values of SOUs and non-SOUs, this section proceeds with six different economy-wide fixed asset series, all in constant year 2000 prices. Except in the fourth scenario, all economy-wide series are obtained as the sum of SOU and non-SOU fixed assets. ${ }^{62}$ The six series, ordered by what scrap rates they use, are:

$$
\text { scrap rate of } 0 \% \text { (method "B” for SOUs, "C.3" for pre-1986 non-SOU values); }
$$


(2) scrap rate of $1 \%(\mathrm{~B}, \mathrm{C} .3)$;

(3) depreciation-based scrap rates $(\mathrm{B}, \mathrm{E})$;

(4) depreciation-based scrap rates (economy- wide investment);

(5) investment-based scrap rates (B, C.3);

(6) investment-based scrap rates (B and C.3, both augmented in the years through 1986 by that factor which raises the 1992 sum of SOU nominal effective investment to the SOU 1992 benchmark value of original fixed assets).

The scrap rates are those reported in Table 5 with the alternative values since 1993. Table 7 has the final economy-wide (sum of SOUs and non-SOUs) midyear fixed asset values in constant year 2000 prices. These fixed asset values reflect the costs of putting the production capacity of a particular year in place, at year 2000 constant prices.

A scrap rate of $0 \%$, in the first scenario, can be justified as follows. If the SOU benchmark original value of fixed assets for 1980 (or 1981, or 1982) and that for 1992 (or 1991) are combined with the official data on SOU effective investment, the result is an average annual scrap rate of between negative $1.11 \%$ and negative $1.23 \%$; even if the data on newly increased fixed assets of 1981 through 1985 are augmented by the ratio of gross fixed capital formation to total investment (Figure 1), the average annual scrap rate remains negative at $0.87 \%$ (1980-92). A scrap rate of $0 \%$ then even appears an overestimate. ${ }^{63}$ Independently, the annual investment-based scrap rates, except in the second half of the 1990 s, hover around $0 \%$.

A scrap rate of $1 \%$ can be justified through a thought experiment. Taking the average annual real growth rate of economy-wide effective investment in 1986-2000, when the data are presumably rather reliable, of $9.9071 \%$, and the average annual increase in the deflator in this period, of $7.3975 \%$, implies a $0.98 \%$ scrap rate when the lifetime of fixed assets in China is 30 years; a 25 -year lifetime implies a scrap rate of $2.17 \%$, and a 40 -year lifetime of $0.20 \% .{ }^{64}$ Alternatively, using the average annual increase in the deflator in the period 1953 2000 (rather than 1986-2000), of 2.8484\%, while retaining the (available) average annual real growth rate of effective investment in 1986-2000, the three scrap rates are 3.08\% (30-year lifetime), 5.61\% (25-year lifetime), and $0.93 \%$ (40-year lifetime). A 40-year lifetime well into the reform period appears plausible, as does a 30-year lifetime, with a higher deflator, for the most recent years of the reform period. Independently, a scrap rate of around one percent is also suggested by the probably quite accurate depreciation-based scrap rates.

The third and fourth scenarios use depreciation-based scrap rates. In the third scenario, non-SOU investment prior to 1986 is derived as residual of gross fixed capital formation and SOU investment; this corrects for possibly underreported investment. In the fourth scenario, investment values are gross fixed capital formation through 1985 and econo my-wide investment since $1986 .{ }^{65}$ The fifth and sixth scenarios use investment-based scrap rates; these are likely to compensate for possibly underreported official investment. In the fifth scenario, non-SOU effective investment is obtained by applying non-SOU industrial gross output value real growth rates to the 1986 (real) value of effective investment. The final, sixth scenario assumes that the 1992 SOU benchmark value is perfectly accurate and adjusts SOU and nonSOU effective investment in each year prior to 1986 by that constant factor (1.174394) which makes the cumulative SOU series in 1992 reach the benchmark value.

Figure 2 and Figure 3 present the annual (real) growth rates of the six series of economywide midyear fixed asset values, first for the period since 1955 (mid-year values are only 
available since 1954), and then in a close-up for the reform period. A chart of absolute values would provide no insights because the trends in absolute values are all highly similar.

Figure 2 shows that the different fixed asset series move closely in step except for the two series with investment-based scrap rates (whose growth rates through 1985 are identical by construction) in the second half of the $1950 \mathrm{~s}$ and in the early $1970 \mathrm{~s} .{ }^{66}$ The close-up (Figure 3 ) reveals that the six series form three distinct patterns: the two fixed asset series using constant scrap rates tend to exhibit the highest growth rates, the two using depreciation-based scrap rates the lowest growth rates, and the two using investment-based scrap rates follow a more ragged pattern mostly in between the other two patterns. ${ }^{67}$

The scenario with a scrap rate of $1 \%$ is desirable if one distrusts the annual variation in derived scrap rates. The third scenario with depreciation-based scrap rates and non-SOU pre1986 investment obtained as residual of gross fixed capital formation and SOU investment combines the probably most accurate annual scrap rate series with a broad, perhaps excessively broad coverage of investment prior to 1986; non-SOU investment prior to 1986 is the difference of gross fixed capital formation (possibly an overestimate of economy-wide investment) and SOU investment. ${ }^{68}$ The investment-based scrap rates in the fifth scenario automatically correct for underestimation of effective investment in as far as that is apparent in the SOU and industrial SOE fixed asset data which underlie this scrap rate. Furthermore, the growth rate of non-SOU effective investment prior to 1986 is probably the most accurate possible given its reliance on industrial non-SOU output real growth rates and the choice of 1986 with a reliable effective investment value as starting point. All three fixed asset series are highly plausible; the third could be the best. ${ }^{69}$

\section{Comparisons of Fixed Asset Values}

Economy-wide fixed asset data were constructed based on the national income account data and on the accumulation of investment. This section contrasts the two groups of fixed asset series. The series derived here are also compared to others provided in the literature.

\section{Economy-wide fixed asset values based on NIA vs. cumulative approach}

Figure 4 presents the four NIA fixed asset series. Whether the sum of provincial depreciation data are used in the calculation of the fixed asset series or the across-province depreciation share in GDP is applied to nationwide GDP makes little difference. What matters more is if the approximate depreciation rate is used or a constant (assumed) five percent depreciation rate. In the latter case, the series are much smoother; in levels, all move in line.

In 1993, growth in the fixed asset series based on the approximate depreciation rates plummets to almost zero. 1993 was a year of rapid expansion; a zero real growth rate of fixed assets does not appear credible. The low growth rate coincides with a rise in the depreciation rate by about one percentage point in 1993 (which lowers the ratio of depreciation to the depreciation rate, i.e., fixed assets). This rise in the depreciation rate may be quite accurate because the depreciation rates calculated from depreciation and fixed asset values in industry show a similar jump in 1993 as the published depreciation rates (Table 1). The problem would then rest with the economy-wide depreciation data. 
But provincial income approach value-added, of which depreciation is one component, add up across provinces to match the sum of provincial production approach value-added. Nevertheless, depreciation may be the weakest link in that the income approach is not the official approach to the calculation of GDP and some values may have been guesstimated or obtained as residuals; the adoption of a new accounting system in 1993 may also have hampered data quality in that particular year. The share of depreciation in GDP (both variables as sum across provinces) fell from $12.87 \%$ in 1992 to $11.63 \%$ in 1993 before rising again to $11.91 \%$ in 1994 and $12.35 \%$ in 1995; if the 1993 share had not dipped by more than one percentage point but remained at the 1992 level, fixed assets in 1993 would have grown by $6.93 \%$ (in the case of the approximate depreciation rate).

A further aspect is the revaluations of fixed assets beginning in 1993. If the economywide depreciation values are approximated by the statistical authority initially without taking the revaluations into full consideration, the result is an underestimation of fixed assets in 1993 and gradual incorporation of the revaluations in the years thereafter. Indeed, depreciation grew rapidly in 1994-98 (Table 2, even after accounting for price changes), as did, consequently, fixed assets in 1995 through 1998 (see Figure 4, with a contrarian development in the depreciation rate in 1994, and a supporting one in 1996).

Figure 5 compares the NIA fixed asset series based on the approximate or five percent depreciation rate with the three final fixed asset series from the cumulative investment approach. ${ }^{70}$ Both NIA fixed asset series exhibit larger fluctuations than the ones obtained via the cumulative approach. A 1985 peak in the NIA fixed asset series based on a fixed five percent depreciation rate now stands out almost as much as the 1993 trough in the NIA fixed asset series based on the approximate depreciation rate. The levels of variability in the NIA data for a capital stock series which is moved by annual increases through investment and the decommissioning of some fixed assets appears high. Furthermore, the NIA fixed asset series since 1993 are artificially inflated by revaluation (beyond the price adjustment implemented to obtain a constant price series). This makes them less desirable than those obtained via the cumulative investment approach. The revaluations also inflate the long-run growth in the NIA fixed asset series; these growth rates are about two percentage points above those of the cumulative series (bottom Table 4, Table 7).

\section{Economy-wide original values of fixed assets compared to the literature}

Does the choice of fixed asset series really matter? Do fixed asset series in the literature which take the depreciation rate for a scrap rate (or the accounting artifact of net fixed assets as a measure of fixed assets), gross fixed capital formation for investment, and investment for newly increased assets, not perhaps yield similar results? Figure 6 through Figure 9 compare the results obtained here to those of Gregory Chow (1994) for 1953 through 1985, Gregory Chow and Kui-Wai Li for 1952-1998, Wang Yan and Yao Yudong (2003) for 1952 through 1999, and Wu Yanrui (2004) for 1952 through 2000, where the values in the literature are turned into mid-year values for comparability. ${ }^{71}$

Figure 6 shows the annual growth rates in all four alternative time series to in the early 1980s and in the late 1990s be at the lower end of the series derived here; in the mid-1990s, their growth rates are higher. The average annual real growth rate over the period 1978-99 in the three series in the literature by Wang/Yao, Wu Yanrui, and Chow/Li is 9.43\%, 9.61\%, 
and $9.52 \%$ (1978-98), lower than in the case of the three series derived here of $11.29 \%$, $9.66 \%$, and $10.58 \%$ (scrap rates of $1 \%$, depreciation-based, investment-based; bottom Table 7). For the period 1954-99 the comparison is between $7.79 \%, 8.82 \%$ and $8.33 \%$ (1978-98) in the literature and $11.32 \%, 10.61 \%$ and $11.42 \%$ here. In other words, the literature tends to underestimate the long-run average annual growth rate of capital by three to four percentage points. In the reform period, the difference narrows to at most two percentage points. In a growth accounting exercise, the lower growth rates of fixed assets reduce TFP growth by about half that percentage.

Another approach is to examine the 4-year growth rates (not annualized), which may yet sharpen the conflicts between the different series. Figure 7 does so for the years 1958 (with a real growth rate over 1954) through 2002 and Figure 8 solely for the reform period. All four series in the literature exhibit exceptionally low growth in the late 1950s, and through the early 1990s remain at the lower bound of the estimates in this paper. A four-year growth rate twenty percentage points below those of the series derived in this paper is not a rarity.

Figure 9 relates annual mid-year fixed asset values to GDP (except for Gregory Chow's case, since he does not provide value-added data), all in real terms. ${ }^{72}$ Compared to the fixed asset series developed in this paper, the three series in the literature start at a two to five times higher level of capital relative to GDP. ${ }^{73}$ Wang/Yao's ratio ends in 1999 at a largely unchanged, now lower-range value. Wu Yanrui's ratio remains larger through the mid-1970s, when it begins to drop precipitously; by 2000, one unit of real capital in Wu Yanrui's series produced four times more real value-added than in the mid-1970s. Chow/Li's ratio is by far the highest throughout but shows a long-run falling trend between 1961 and 1998. In contrast to all three series in the literature, the series developed in this paper exhibit a gradually rising capitaloutput ratio over time. This is probably what a development economist would have predicted. In other words, established patterns in economics confirm the fixed asset series derived in this paper but not those in the literature. ${ }^{74}$

\section{Conclusions}

Physical capital series are an indispensable part of economic growth studies. In the absence of official data on economy-wide (or sectoral) fixed asset data, China researchers resort to self-constructed series. When they use official fixed asset data available for some subsets of the economy, they adjust these in an attempt to, among others, obtain a series in fixed prices. The derivation of economy-wide fixed asset series and the adjustments to available fixed asset data are invariably flawed at the conceptual level. Authors use the depreciation rate instead of a scrap rate (apparently unaware of the difference); this paper suggest this is a 500\% overestimate. Alternatively, they correctly use the depreciation rate but then obtain a, in the context of growth and efficiency studies irrelevant, accounting artifact (net fixed assets). Gross fixed capital formation is taken to proxy for investment; this is likely to be an overestimate, potentially a significant one, except in the years since the late 1990s. Whether investment expenditures yield fixed assets of equivalent value is a question that is never raised in the literature; yet the data show that the transfer rate, i.e., the rate at which investment of a given year translates into newly increased fixed assets in that year, can go as low as 50\% (in the case of SOUs, in 1967 and 1968), and stays around 80\%, economy-wide, during the reform period. Revaluations of fixed assets in the mid-1990s can wreak havoc on fixed asset series in the literature and has unaware researchers wondering about why efficiency growth has slumped (it may not have, the meaning of the underlying data changed). 
The result of these approximations is a hodgepodge of contradictory deviations from the (unknown) true fixed asset series. At a time of high inflation, using the depreciation rate instead of the scrap rate tends to underestimate the real capital stock (annual nominal increases, which are to be deflated, are overestimated). On the other hand, at a time of low transfer rates, using the investment data instead of effective investment implies that annual increases in fixed assets are overestimated. The resulting time series may not be terribly far off the mark - otherwise, researchers would probably have already noticed that something is conceptually wrong - but the four economy-wide time series immediately available in the literature all exhibit lower growth rates through the early 1990s, and a different pattern in the 1990s than the series derived here. Year-on-year or four-year growth rates can be significantly off. The fact that the economy-wide capitaloutput ratio according to one time series in the literature has remained approximately constant over 50 years and is on a downward trend according to two others does not make these fixed asset series particularly plausible.

This paper addresses the shortcomings at the conceptual level by laying out how fixed asset variables are related to other variables by the logic of the accounting system. It proceeds to use these identities to construct conceptually correct fixed asset series via investment accumulation. These are supplemented by fixed asset series obtained through a hitherto unexplored direct approach of dividing depreciation in the national income accounts by the depreciation rate. The perhaps most reliable fixed asset series is the one in the cumulative approach with investment-based scrap rates and non-SOU values which take into consideration (estimated) year-specific pre-1986 growth rates of effective investment (fifth data column, Table 7). A fixed asset series using a constant $1 \%$ scrap rate series as well as one using depreciation-based scrap rates with residual investment values for non-SOUs also appear plausible (both in the cumulative approach, second and third data columns, Table 7).

A number of additional variations are possible and the data are provided in this paper to explore these further. For example, the 1992 SOU benchmark value could be taken as the true value and a fixed asset series for SOUs constructed by adding/ subtracting effective investment of all other years from this benchmark value (taking into account the scrap rates and deflating for price changes). If one believes that the gross fixed capital formation data accurately proxy for economy-wide investment, this series could be used for all years (taking into account the scrap rates, transfer rates, and price changes). Or the scrap rates obtained in the cumulative approach could be taken to the NIA approach. Since the results derived in this paper under a wide variety of assumptions do not vary much, further scenarios will probably not yield much different results. The close match of the various cumulative series derived here is good news. While we may not have one perfect fixed asset series, as long as the derivation is conceptually correct, minor variations in assumptions have little impact. 


\section{References}

Chinese names in pinyin form are given last name first, followed by first name, without comma in between.

Chen Kuan, Gary H. Jefferson, Thomas G. Rawski, Wang Hongchang and Zheng Yuxin. "New Estimates of Fixed Investment and Capital Stock for Chinese State Industry." The China Quarterly, no. 114 (June 1988): 243-66

Chow, Gregory. Understanding China's Economy. Singapore: World Scientific Publishing Company, 1994.

Chow, Gregory C., and Kui-Wai Li. "China's Economic Growth: 1952-2010.” Economic Development and Cultural Change 51, no. 1 (Oct. 2002): 247-56.

Finance Ministry. All regulations from China Infobank at www. chinainfobank.com.

21 Sept. 1992. Guanyu guoying qiye shixing guding zichan jiazhi chonggu hou jiti zhejiu caiwu chuli wenti de tongzhi (Circular on the procedures involved in accounting for depreciation following revaluation of fixed assets in state-owned enterprises).

21 Sept. 1998. Guanyu zuohao richang qingchan hezi gongzuo youguan wenti de tongzhi

(Circular on some issues in the day-to-day revaluation work). Caiqingzi no. 14 (1998).

Finance Ministry (General Office). Xianxing caiwu kuaiji zhidu quanshu (Almanac on the current financial and accounting system). Two volumes. Beijing: Zhongguo caizheng jingji chubanshe, 1999.

Fiscal Yearbook. Zhongguo caizheng nianjian (China Fiscal Yearbook). Beijing: Zhongguo caizheng zazhishe, various years.

GDP 1952-95. Zhongguo guonei shengchan zongzhi hesuan lishi ziliao 1952-1995 (Historical data on China's gross domestic product 1952-1995). Dalian: Dongbei caijing daxue chubanshe, 1997.

GDP Manual. Zhongguo guonei shengchan zongzhi hesuan shouce (Manual for the calculation of GDP in China). Compiled by the NBS National Income Accounting Division, 2001.

Holz, Carsten A. "Institutional Constraints on the Quality of Statistics in China." China Information 16, no. 1 (2002): 25-67. . "Deconstructing China's GDP Statistics." China Economic Review 15, no. 2 (2004): 164-202.

Holz, Carsten A., and Yi- min Lin. "Pitfalls of China's Industrial Statistics: Inconsistencies and Specification Problems." The China Review 1, no. 1 (Fall 2001): 29-71.

Industrial Yearbook. Zhongguo gongye jingji tongji nianjian (China Industrial Economy Statistical Yearbook). Beijing: Zhongguo tongji chubanshe, various years. (Early issues were titled Zhongguo gongye jingji tongji ziliao, China Industrial Economy Statistical Material.)

Investment 1950-2000. Zhongguo guding zichan touzi tongji shudian 1950-2000 (Statistics on investment in fixed assets in China 1950-2000). Beijing: Zhongguo tongji chubanshe, 2002.

Investment Materials 1950-1985. Zhongguo guding zichan touzi tongji ziliao (China Investment in Fixed Assets Statistical Materials). Beijing: Zhongguo tongji chubanshe, 1987.

Investment Revaluation 1984-2000. 1984-2000 nian quanguo guding zichan jiazhi chong(ping)gu xishu biaozhun mulu (Standard list of national 1984-2000 fixed asset value revaluation factors). Beijing: Zhongguo tongji chubanshe, 2001 (two volumes). 
Investment Yearbook. Zhongguo guding zichan touzi tongji nianjian (China Investment in Fixed Assets Yearbook). Beijing: Zhongguo tongji chubanshe, various issues.

Jefferson, Gary H., Thomas G. Rawski, and Zheng Yuxin. "Growth, Efficiency, and Convergence in China's State and Collective Industry." Economic Development and Cultural Change 40, no. 2 (Jan. 1992): 239-66. . "Chinese Industrial Productivity: Trends, Measurement Issues, and Recent Developments." Journal of Comparative Economics 23, no. 2 (1996): 146-80.

Jefferson, Gary H., Thomas G. Rawski, Wang Li and Zheng Yuxin. 'Ownership, Productivity Change, and Financial Performance in Chinese Industry." Journal of Comparative Economics 28, no. 4 (Dec. 2000): 786-813.

NBS (National Bureau of Statistics) 1997. Zhongguo niandu guonei shengchan zongzhi jisuan fangfa (Method of calculating China's annual GDP). Issued by the NBS National Income Accounts Division. Beijing: Zhongguo tongji chubanshe, 1997.

SC (State Council). All regulations from China Infobank at www. chinainfobank.com. 3 May 1993. Qingchan hezi banfa (Revaluation measures). Guoqing no. 78 (1993). 14 May 1993. Qingchan hezi zichan jiazhi chonggu shishi xize (Implementing instructions on the revaluation of assets). Guoqing no. 81 (1993).

Statistical Yearbook. Zhongguo tongji nianjian (Statistical Yearbook of China). Beijing: Zhongguo tongji chubanshe, various years.

Tertiary Sector Census 1993. Zhongguo shouci di san chanye pucha ziliao: 1991 1992 (Materials on China's first tertiary sector census: 1991-1992). Four volumes (with continuing page numbers). Beijing: Zhongguo tongji chubanshe, 1995.

TVE Yearbook 2003. Zhongguo xiangzhen qiye nianjian 2003 (China Township [and Village] Enterprise Yearbook 2003). Beijing: Zhongguo nongye chubanshe, 2003.

Wang Yan and Yao Yudong. "Sources of China's Economic Growth 1952-1999:

Incorporating Human Capital Accumulation." China Economic Review 14, no. 1 (2003): 32-52.

Wu Yanrui. China's Economic Growth: A Miracle with Chinese Characteristics. London and New York: RoutledgeCurzon, 2004.

$\mathrm{Xu}$ Xianchun. Zhongguo guonei shengchan zongzhi hesuan (Calculation of China's GDP). Beijing: Beijing daxue chubanshe, 2000.

Young, Alwyn. "Gold into Base Metals: Productivity Growth in the People's Republic of China during the Reform Period." Journal of Political Economy 111, no. 6 (Dec. 2003): 1220-61. 
Table 1. Fixed Asset Depreciation Rates and Deflator

\begin{tabular}{|c|c|c|c|c|c|c|c|c|c|}
\hline & \multicolumn{7}{|c|}{ Depreciation rates of fixed assets (in \%) } & \multirow{2}{*}{\multicolumn{2}{|c|}{$\begin{array}{l}\text { Deflator of } \\
\text { fixed assets } \mathrm{f}^{\mathrm{f}}\end{array}$}} \\
\hline & & \multicolumn{3}{|c|}{ State-owned enterprises: } & \multirow{2}{*}{$\begin{array}{l}\text { Dir. rep. } \\
\text { industry }\end{array}$} & \multirow{2}{*}{\multicolumn{2}{|c|}{$\begin{array}{l}\text { Economy-wide } \\
5 \text { approxi- } \\
\text { prov. }^{\text {e }} \text { mated }\end{array}$}} & & \\
\hline & $\begin{array}{c}\text { total }^{\mathrm{a}} \\
\text { (budget.) }\end{array}$ & $\begin{array}{l}\text { industry }^{\mathrm{a}} \\
\text { (budget.) }\end{array}$ & industry $^{\mathrm{b}}$ & $\begin{array}{l}\text { industry }^{\mathrm{c}} \\
\text { (prov.) }\end{array}$ & & & & $\begin{array}{c}\text { prev. } y \\
=100\end{array}$ & $\begin{array}{c}2000 \\
=100\end{array}$ \\
\hline 1953 & 2.9 & 3.7 & & & & & & 98.8 & 26.71 \\
\hline 1954 & 3.1 & 4.1 & & & & & & 99.4 & 26.55 \\
\hline 1955 & 3.3 & 4.2 & & & & & & 95.7 & 25.41 \\
\hline 1956 & 3.3 & 4.1 & & & & & & 99.7 & 25.34 \\
\hline 1957 & 3.1 & 3.7 & & & & & & 95.7 & 24.26 \\
\hline 1958 & [3.3] & [3.9] & & & & & & 100.3 & 24.35 \\
\hline 1959 & [3.5] & [4.2] & & & & & & 108.4 & 26.38 \\
\hline 1960 & 3.7 & 4.4 & & & & & & 99.7 & 26.30 \\
\hline 1961 & 3.4 & 4.1 & & & & & & 98.2 & 25.82 \\
\hline 1962 & 3.2 & 3.6 & & & & & & 107.4 & 27.72 \\
\hline 1963 & 3.1 & 3.7 & & & & & & 104.8 & 29.06 \\
\hline 1964 & 3.2 & 3.8 & & & & & & 97.9 & 28.46 \\
\hline 1965 & 3.2 & 3.8 & & & & & & 96.7 & 27.52 \\
\hline 1966 & 3.3 & 3.9 & & & & & & 98.1 & 26.99 \\
\hline 1967 & 3.0 & 3.6 & & & & & & 100.3 & 27.08 \\
\hline 1968 & 3.0 & 3.6 & & & & & & 96.6 & 26.15 \\
\hline 1969 & 3.1 & 3.7 & & & & & & 97.7 & 25.55 \\
\hline 1970 & 3.2 & 3.8 & & & & & & 100.0 & 25.54 \\
\hline 1971 & 3.2 & 3.8 & & & & & & 101.1 & 25.82 \\
\hline 1972 & 3.5 & 4.0 & & & & & & 101.3 & 26.14 \\
\hline 1973 & 3.4 & 3.9 & & & & & & 100.1 & 26.17 \\
\hline 1974 & 3.5 & 3.9 & & & & & & 100.1 & 26.20 \\
\hline 1975 & 3.6 & 4.0 & & & & & & 101.2 & 26.52 \\
\hline 1976 & 3.6 & 4.0 & & & & & & 100.7 & 26.70 \\
\hline 1977 & 3.7 & 4.1 & & & & & & 101.5 & 27.10 \\
\hline 1978 & 3.7 & 4.1 & & & & & 3.7 & 100.6 & 27.25 \\
\hline 1979 & 3.7 & 4.2 & & & & & 3.8 & 102.2 & 27.83 \\
\hline 1980 & 4.1 & 4.2 & & & & & 3.8 & 103.1 & 28.69 \\
\hline 1981 & 4.1 & 4.3 & & & & & 3.9 & 103.2 & 29.60 \\
\hline 1982 & 4.1 & 4.3 & & & & & 3.9 & 102.3 & 30.28 \\
\hline 1983 & 4.2 & 4.4 & & & & & 4.0 & 102.5 & 31.03 \\
\hline 1984 & 4.4 & 4.6 & & & & & 4.1 & 104.0 & 32.29 \\
\hline 1985 & 4.7 & 5.0 & 4.41 & & 4.76 & & 4.4 & 107.2 & 34.60 \\
\hline 1986 & 4.9 & 5.1 & 4.46 & & 4.89 & & 4.5 & 106.4 & 36.82 \\
\hline 1987 & 4.9 & 5.2 & 4.50 & & 4.90 & & 4.5 & 105.3 & 38.75 \\
\hline 1988 & 5.0 & 5.3 & 4.61 & & & & 4.6 & 113.5 & 43.99 \\
\hline 1989 & 5.0 & 5.3 & 4.59 & & 5.05 & & 4.6 & 108.5 & 47.73 \\
\hline 1990 & 4.8 & 5.1 & 4.43 & & 4.90 & & 4.4 & 105.5 & 50.35 \\
\hline 1991 & 5.5 & 5.5 & 4.59 & (4.48) & 5.04 & & 4.6 & 109.5 & 55.13 \\
\hline 1992 & 5.5 & 5.7 & & 4.67 & & & 4.7 & 115.3 & 63.56 \\
\hline 1993 & [6.6] & 6.6 & & 5.50 & & & 5.5 & 126.6 & 80.47 \\
\hline 1994 & [6.5] & (6.5) & & 5.94 & & & 5.9 & 110.4 & 88.84 \\
\hline 1995 & [6.3] & (6.3) & & 5.78 & & & 5.8 & 105.9 & 94.08 \\
\hline 1996 & [5.7] & (5.7) & & 5.03 & & & 5.0 & 104.0 & 97.84 \\
\hline 1997 & [5.1] & (5.1) & & 4.78 & & & 4.8 & 101.7 & 99.51 \\
\hline 1998 & [5.8] & (5.8) & & 4.20 & & & 4.2 & 99.8 & 99.31 \\
\hline 1999 & & [6.0] & & 4.44 & & & 4.5 & 99.6 & 98.91 \\
\hline 2000 & & [6.1] & & 4.52 & & 4.96 & 4.7 & 101.1 & 100.00 \\
\hline 2001 & & [6.4] & 5.14 & $(5.12)$ & 5.47 & & 5.2 & 100.4 & 100.40 \\
\hline
\end{tabular}


All depreciation rates except those in the first two data columns are calculated; calculations are based on data for depreciation and the midyear original value of fixed assets (sum of previous year end-year value plus current year end-year value, divided by two), except in the case of the 5 provinces in 2000, where only end-year original values of fixed assets are available and used.

a The original data are depreciation rate data. These data presumably cover the budgetary SOEs only. The table with the original data lists "basic depreciation rates" (jiben zhejiu lu) in the categories total, industry, railway, communications, commerce, and grain.

The depreciation rates in curved parentheses, in the case of industry, are derived from provinciallevel original values of fixed assets and provincial-level depreciation rates; provincial-level end-year original values of fixed assets are used as weights in the derivation of the nationwide depreciation rate. (Both, depreciation rates and original values of fixed assets are in the same section of the Fiscal Yearbook (pp. 487, 489), separated only by one page of net fixed assets, in similar tables with the same coverage across provinces and years.) Provincial original values of fixed assets do not cover central enterprises located in a particular province, except in 1998, when the sum across provinces equals the national total (in the Fiscal Yearbook 1999, p. 481). The sum of original values of fixed assets across provinces is approximately half the nationwide value in 1991 through 1997.

The depreciation rates in square brackets are assumed. The depreciation rate of budgetary SOEs after 1992 is assumed to follow that of budgetary industrial SOEs, and that of budgetary industrial SOEs after 1998 is taken to follow the trends in the industry depreciation rates available according to other definitions.

b Current-year depreciation divided by the current-year midyear original value of fixed as sets. The enterprise coverage is all industrial SOEs (since 1998 including state-controlled enterprises).

c Same as in b, but depreciation and original value of fixed asset data are for individual provinces (from provincial statistical yearbooks); the depreciation rate reported is the weighted mean across those provinces for which the data are available (weighted by the midyear original value of fixed assets). The number of provinces on which data are available in 1992 through 2000 is $8,6,7,8,9,10,8,8,7$. The ten provinces in 1997 are Beijing, Jilin, Anhui, Hubei, Hunan, Tibet, Shaanxi, Gansu, Qinghai, and Xinjiang; fewer provinces in other years are a subset of these ten. For 1991 and 2001, data on all provinces are available, but only those of the ten provinces are used. The 1998 through 2000 SOE coverage is not clear for all provinces; different provinces switched from "SOEs" to "SOEs and state-controlled enterprises" in different years.

d Same as in b, but the coverage is all directly reporting industrial enterprises.

e Unweighted mean across five provinces: current-year economy-wide depreciation in the national income accounts divided by end-year original value of fixed assets in the provincial economy -wide balance sheet. Since the denominator contains end-year rather than midyear values, this depreciation rate is an underestimate. The five provinces for which fixed asset values are available in the provincial statistical yearbooks (out of all provinces) are Anhui (with a depreciation rate of 6.37\%), Henan (4.36\%), Hebei (5.17\%), Shaanxi (4.86\%), and Shanghai $(4.05 \%)$. Only for Shaanxi is a 1999 original value of fixed assets available, implying a ratio of year 2000 depreciation to midyear original value of fixed assets of $5.29 \%$ instead of $4.86 \%$.

f The investment in fixed asset deflator is the implicit deflator of gross fixed capital formation in the years 1953 through 1990, and the since 1991 available investment in fixed asset price index.

Sources:

Basic depreciation rates of all budgetary SOEs and of industrial budgetary SOEs: Statistical Yearbook 1990, p. 30; 1995, p. 29; Fiscal Yearbook 1993, p. 685; provincial data on industrial budgetary SOEs: Fiscal Yearbook 1999 , pp. 487, 489.

Third and fifth data column: depreciation: Industrial Yearbook 1986, p. 21; Statistical Yearbook 1987, pp. 310,$314 ; 1988$, pp. 376, 377; 1989, p. 324; 1990, p. 421; 1991, p. 401; 1992, p. 413; Industrial Yearbook 2002 , p. 61;2003, p. 61;2004, p. 57; original value of fixed assets: Statistical Yearbook 1993, p. 430; Industrial Yearbook 1993, p. 65;2004, pp. 25f.

Fourth data column: depreciation and original value of fixed assets: individual provincial yearbooks of individual years (all provinces were checked); missing original value of fixed asset data for Xinjiang in 1999 and 2000 are from the Statistical Yearbook 2000, p. 431;2001, p. 427.

Sixth data column: provincial original fixed asset data are from provincial statistical yearbooks of Anhui (2002, pp. 78f.), Henan (2002, pp. 58-61), Hebei (2002, pp. 202f.), Shaanxi (2002, pp. 55-7), and Shanghai (2004, p. 47); depreciation data are from the national income accounts in the Statistical Yearbook 2001, p. 60.

Last two data column s (fixed asset deflator): for 1953-90 calculated from nominal data and real growth rates of gross fixed capital formation in GDP 1952-95, pp. 50, 51; investment in fixed asset price index for the years since 1991 from Statistical Yearbook 2004, p. 323. 
Table 2. Economy-wide Depreciation (b yuan RMB)

\begin{tabular}{|c|c|c|c|c|c|c|c|c|}
\hline & \multicolumn{4}{|c|}{ Sum across provinces (1996- as first published) } & \multicolumn{4}{|c|}{ National data } \\
\hline & \multirow{2}{*}{$\begin{array}{l}\text { Prod. appr. } \\
\text { GDP }\end{array}$} & \multicolumn{3}{|c|}{ Income approach } & \multicolumn{2}{|c|}{ Revised data } & \multicolumn{2}{|c|}{ Original data } \\
\hline & & GDP & Deprec. & D. in $\%$ & $\begin{array}{l}\text { Prod. appr. } \\
\text { GDP } \\
\text { (4) }\end{array}$ & $\begin{array}{l}\text { Implied } \\
\text { deprec. } \\
(3) /(2)^{*}(4)\end{array}$ & $\begin{array}{l}\text { Prod. appr. } \\
\text { GDP } \\
\text { (5) }\end{array}$ & $\begin{array}{l}\text { Implied } \\
\text { deprec. } \\
(3) /(2)^{*}(5)\end{array}$ \\
\hline 1978 & 344.049 & 344.049 & 33.394 & 9.7062 & 362.41 & 35.18 & & \\
\hline 1979 & 391.799 & 391.799 & 37.679 & 9.6169 & 403.82 & 38.84 & & \\
\hline 1980 & 436.787 & 436.787 & 42.883 & 9.8178 & 451.78 & 44.35 & & \\
\hline 1981 & 475.960 & 475.960 & 47.464 & 9.9723 & 486.24 & 48.49 & & \\
\hline 1982 & 529.158 & 529.158 & 53.004 & 10.0167 & 529.47 & 53.04 & & \\
\hline 1983 & 593.977 & 593.977 & 60.131 & 10.1235 & 593.45 & 60.08 & & \\
\hline 1984 & 708.827 & 708.897 & 70.828 & 9.9913 & 717.1 & 71.65 & & \\
\hline 1985 & 861.903 & 857.740 & 85.331 & 9.9484 & 896.44 & 89.18 & & \\
\hline 1986 & 965.361 & 961.045 & 100.795 & 10.4881 & 1020.22 & 107.00 & & \\
\hline 1987 & 1145.521 & 1139.898 & 122.525 & 10.7488 & 1196.25 & 128.58 & & \\
\hline 1988 & 1446.118 & 1438.852 & 153.527 & 10.6701 & 1492.83 & 159.29 & & \\
\hline 1989 & 1637.843 & 1629.663 & 184.277 & 11.3077 & 1690.92 & 191.20 & 1579.37 & 178.59 \\
\hline 1990 & 1834.815 & 1835.723 & 214.284 & 11.6730 & 1854.79 & 216.51 & 1767.11 & 206.27 \\
\hline 1991 & 2112.774 & 2114.201 & 260.608 & 12.3265 & 2161.78 & 266.47 & 1984.06 & 244.57 \\
\hline 1992 & 2587.929 & 2589.232 & 333.173 & 12.8676 & 2663.81 & 342.77 & 2402.02 & 309.08 \\
\hline 1993 & 3418.793 & 3420.906 & 397.812 & 11.6288 & 3463.44 & 402.76 & 3138.03 & 364.92 \\
\hline 1994 & 4538.369 & 4538.369 & 540.688 & 11.9137 & 4675.94 & 557.08 & 4500.58 & 536.19 \\
\hline 1995 & 5762.332 & 5763.278 & 711.633 & 12.3477 & 5847.81 & 722.07 & 5826.05 & 719.38 \\
\hline 1996 & 6858.430 & 6858.430 & 878.142 & 12.8038 & 6788.46 & 869.18 & 6859.38 & 878.26 \\
\hline 1997 & 7695.661 & 7695.661 & 1048.641 & 13.6264 & 7446.26 & 1014.66 & 7477.24 & 1018.88 \\
\hline 1998 & 8278.025 & 8278.025 & 1198.124 & 14.4735 & 7834.52 & 1133.93 & 7939.57 & 1149.14 \\
\hline 1999 & 8767.113 & 8767.113 & 1320.904 & 15.0666 & 8206.75 & 1236.48 & 8191.09 & 1234.12 \\
\hline 2000 & 9720.937 & 9720.937 & 1497.242 & 15.4022 & 8946.81 & 1378.01 & 8940.36 & 1377.02 \\
\hline 2001 & 10676.626 & 10676.626 & 1677.928 & 15.7159 & 9731.48 & 1529.39 & 9593.33 & 1507.68 \\
\hline 2002 & 11802.069 & 11802.069 & 1849.377 & 15.6699 & 10517.23 & 1648.04 & 10479.06 & 1642.06 \\
\hline 2003 & 13553.914 & 13553.914 & 2155.147 & 15.9006 & 11725.19 & 1864.37 & 11725.19 & 1864.37 \\
\hline
\end{tabular}

Original data are as first published. National production approach GDP is first published in the Statistical Yearbook of the following year (starting with the 1990 issue); a revised national figure is published a year later; a benchmark revision following the tertiary sector census of 1993 revised the data of all earlier years. At the national level, income approach data are not published. A revised production approach GDP figure for 2003 is not yet available; the figure in the Statistical Yearbook 2004 is the original figure.

Provincial production approach GDP, income approach GDP and (income approach) depreciation in the Statistical Yearbook are only published once, in the Statistical Yearbook of the following year (with values for 1993, 1994, and 1996 on); revised data are not published. In the table, the provincial data for 1978-1995 are from the compendium GDP 1952-95. The data for 1978 through 1995 are probably final data, compiled once, retrospectively. The Statistical Yearbook beginning for the year 1993 reports provincial production approach value-added that adds up to GDP in 1993 of $3206.999 \mathrm{~b}$, in 1994 of 4558.634 , and in 1995 of 5763.278 b yuan RMB, $6.20 \%, 0.45 \%$, and $0.02 \%$ lower than the GDP 1952-95 figures, which could imply that the GDP 1952-95 data for the years 1978 through 1995 are the most up-to-date data (the ones in the Statistical Yearbook are as first published). The 1993 difference could be attributed to possibly pre-tertiary sector census provincial data in the Statistical Yearbook.

Tibet is only included starting 1985 , with a value of depreciation equal to $0.12 \%$ of the sum of depreciation across all provinces.

Sources: Sum across provinces: 1978-95: GDP 1952-95, tables of each province; 1996-2003:

Statistical Yearbook of each year, for example, for 2003, Statistical Yearbook 2004, pp. 61, 64. National GDP data: revised series: Statistical Yearbook 2004, p. 53; as first published (original data): Statistical Yearbook of each year (in 1989-91 as sum of three economic sectors). 
Table 3. Average Annual Economy-wide Original Values of Fixed Assets, b yuan RMB

\begin{tabular}{|c|c|c|c|c|c|c|}
\hline & \multicolumn{6}{|c|}{ Based on } \\
\hline & approxil & nate depreciat & $\mathrm{nr}$ & assum & depreciation ra & of $5 \%$ \\
\hline & & and absolute $\mathrm{c}$ & lenrecio & $h$ are obtc & ed as/ in form & \\
\hline & sum across & implied & values - & sum across & implied & values - \\
\hline & & $\begin{array}{l}\text { national deprec } \\
\text { revised GDP }\end{array}$ & $\begin{array}{c}\text { iation based on } \\
\text { original GDP }\end{array}$ & & $\begin{array}{l}\text { national depre } \\
\text { revised GDP }\end{array}$ & $\begin{array}{l}\text { iation based on } \\
\text { original GDP }\end{array}$ \\
\hline 1978 & 902.541 & 950.71 & & 667.880 & 703.52 & \\
\hline 1979 & 991.553 & 1021.98 & & 753.580 & 776.70 & \\
\hline 1980 & 1128.500 & 1167.24 & & 857.660 & 887.10 & \\
\hline 1981 & 1217.026 & 1243.31 & & 949.280 & 969.78 & \\
\hline 1982 & 1359.077 & 1359.88 & & 1060.080 & 1060.71 & \\
\hline 1983 & 1503.275 & 1501.94 & & 1202.620 & 1201.55 & \\
\hline 1984 & 1727.512 & 1747.50 & & 1416.560 & 1432.95 & \\
\hline 1985 & 1939.341 & 2026.84 & & 1706.620 & 1783.62 & \\
\hline 1986 & 2239.889 & 2377.81 & & 2015.900 & 2140.03 & \\
\hline 1987 & 2722.778 & 2857.38 & & 2450.500 & 2571.64 & \\
\hline 1988 & 3337.543 & 3462.75 & & 3070.540 & 3185.73 & \\
\hline 1989 & 4006.022 & 4156.60 & 3882.39 & 3685.540 & 3824.07 & 3571.80 \\
\hline 1990 & 4870.091 & 4920.67 & 4688.06 & 4285.680 & 4330.19 & 4125.50 \\
\hline 1991 & 5665.391 & 5792.89 & 5316.65 & 5212.160 & 5329.46 & 4891.32 \\
\hline 1992 & 7088.787 & 7292.97 & 6576.24 & 6663.460 & 6855.39 & 6181.66 \\
\hline 1993 & 7232.945 & 7322.88 & 6634.85 & 7956.240 & 8055.16 & 7298.34 \\
\hline 1994 & 9164.203 & 9442.00 & 9087.90 & 10813.760 & 11141.56 & 10723.72 \\
\hline 1995 & 12269.534 & 12449.50 & 12403.17 & 14232.660 & 14441.42 & 14387.68 \\
\hline 1996 & 17562.840 & 17383.66 & 17565.27 & 17562.840 & 17383.66 & 17565.27 \\
\hline 1997 & 21846.688 & 21138.68 & 21226.63 & 20972.820 & 20293.13 & 20377.56 \\
\hline 1998 & 28526.762 & 26998.41 & 27360.42 & 23962.480 & 22678.66 & 22982.75 \\
\hline 1999 & 29353.422 & 27477.25 & 27424.82 & 26418.080 & 24729.53 & 24682.34 \\
\hline 2000 & 31856.213 & 29319.34 & 29298.21 & 29944.840 & 27560.18 & 27540.31 \\
\hline 2001 & 32267.846 & 29411.34 & 28993.81 & 33558.560 & 30587.80 & 30153.57 \\
\hline 2002 & 36262.294 & 32314.58 & 32197.30 & 36987.540 & 32960.87 & 32841.25 \\
\hline 2003 & 39910.130 & 34525.37 & 34525.37 & 43102.940 & 37287.40 & 37287.40 \\
\hline
\end{tabular}

Approximate depreciation rate series: see Table 1.

Absolute depreciation values: see Table 2. National depreciation is obtained as "sum provincial depreciation divided by sum provincial gross value-added" times national GDP (at original or revised values). 
Table 4. Average Annual Economy-wide Fixed Asset Values in Year 2000 Constant Prices, billion (year 2000) yuan RMB

\begin{tabular}{|c|c|c|c|c|c|c|c|c|c|}
\hline \multirow[b]{6}{*}{ Sc.r. } & \multirow{6}{*}{$\begin{array}{l}\text { Cumu- } \\
\text { lative } \\
\text { deflator } \\
(2000 \\
=100)\end{array}$} & \multicolumn{8}{|c|}{ Economy-wide original values of fixed assets, b yuan RMB, based on } \\
\hline & & \multirow{2}{*}{\multicolumn{8}{|c|}{$\begin{array}{l}\text { approximate depreciation rate series assumed depreciation rate } \\
\text { and absolute depreciation values which are obtained as/in form of }\end{array}$}} \\
\hline & & & & & & & & & \\
\hline & & \multirow{2}{*}{\multicolumn{2}{|c|}{ sum across provinces }} & \multirow{2}{*}{\multicolumn{2}{|c|}{$\begin{array}{c}\text { implied values - } \\
\text { based on revis. GDP }\end{array}$}} & \multirow{2}{*}{\multicolumn{2}{|c|}{ sum across provinces }} & \multirow{2}{*}{\multicolumn{2}{|c|}{$\begin{array}{c}\text { implied values - } \\
\text { based on revis. GDP }\end{array}$}} \\
\hline & & & & & & & & & \\
\hline & & $0 \%$ & $1 \%$ & $0 \%$ & $1 \%$ & $0 \%$ & $1 \%$ & $0 \%$ & $1 \%$ \\
\hline 8 & 2 & 5 & 5 & & 3489. & 2 & 245 & 582.09 & (0) \\
\hline & & & & & & & 2 & 00 & \\
\hline & & & & & & & & & \\
\hline & 29.60 & & & & & & & & \\
\hline & 30.28 & 1 & 3 & & & 77 & 07 & 0 & 923.74 \\
\hline & 31.03 & & & & & 425 & 440 & 263.27 & \\
\hline & 29 & & & & & 6 & o & 94 & \\
\hline & 60 & & & & & 1 & 8 & .29 & \\
\hline & 2 & & & & & & & & \\
\hline & .75 & & & & & 0 & 8 & .99 & \\
\hline & 43.99 & & & & 10 & 60 & & 81 & .07 \\
\hline & 47.73 & & & & 12 & 92 & 20 & .25 & 26 \\
\hline & & & & & & & & & \\
\hline & & & & & & & & & \\
\hline 19 & 63.56 & & & & 18 & 49 & 16 & .79 & 15 \\
\hline 15 & 47 & 7 & 50 & 17 & 18 & 79.165 & 1793 & .73 & 28 \\
\hline & & & & & 208 & 42 & & 20 & \\
\hline & .08 & & & & & & 1 & & \\
\hline & 97.84 & 22 & & 2 & 292 & 47 & 2854 & 33 & \\
\hline 1997 & 99.51 & 1 & 21 & 98 & 3321 & 79 & 32 & 18 & 11 \\
\hline & & 33002 & & 377 & $393 ?$ & 35 & 35365 & 32832.30 & 34347.58 \\
\hline & 3.91 & & & & 40088. & & 38090 & 34905.73 & 36650.29 \\
\hline & & & & & & & & 37736.38 & \\
\hline 2001 & 100.40 & 42751.289 & 45 & 401 & 42589.23 & 43479.129 & 45778 & 40751.94 & 3018.29 \\
\hline & 100.60 & 46721.882 & 49515.562 & 430 & 45767. & 46887.631 & 49520.629 & 43110.8 & 40001.25 \\
\hline 2003 & 102.81 & 50269.876 & 53416.255 & 45189.48 & 48232.06 & 52835.653 & 55828.403 & 47318.95 & 50209.94 \\
\hline
\end{tabular}

Average annual growth rate (in \%)

\begin{tabular}{lllllllll}
$78-99$ & 12.57 & 12.82 & 12.07 & 12.33 & 13.70 & 13.96 & 13.20 & 13.47 \\
$78-00$ & 12.28 & 12.53 & 11.73 & 12.00 & 13.52 & 13.77 & 12.97 & 13.23 \\
$78-02$ & 11.66 & 11.93 & 11.04 & 11.32 & 13.08 & 13.34 & 12.45 & 12.72 \\
\hline
\end{tabular}

Sc.r.: Scrap rate (of $0 \%$ or $1 \%$ ).

Deflator: 1978-1990: implicit gross fixed capital formation; 1991-2003: investment in fixed assets price index. (For sources see Table 1.)

Economy -wide original value of fixed assets: values from Table 3, annual absolute nominal changes (and 1978 total) deflated to year 2000 constant prices, where in the case of the $1 \%$ scrap rate the absolute nominal changes are first reduced by $1 \%$ of earlier-year (first-year in the difference) original (nominal) value of fixed assets. 


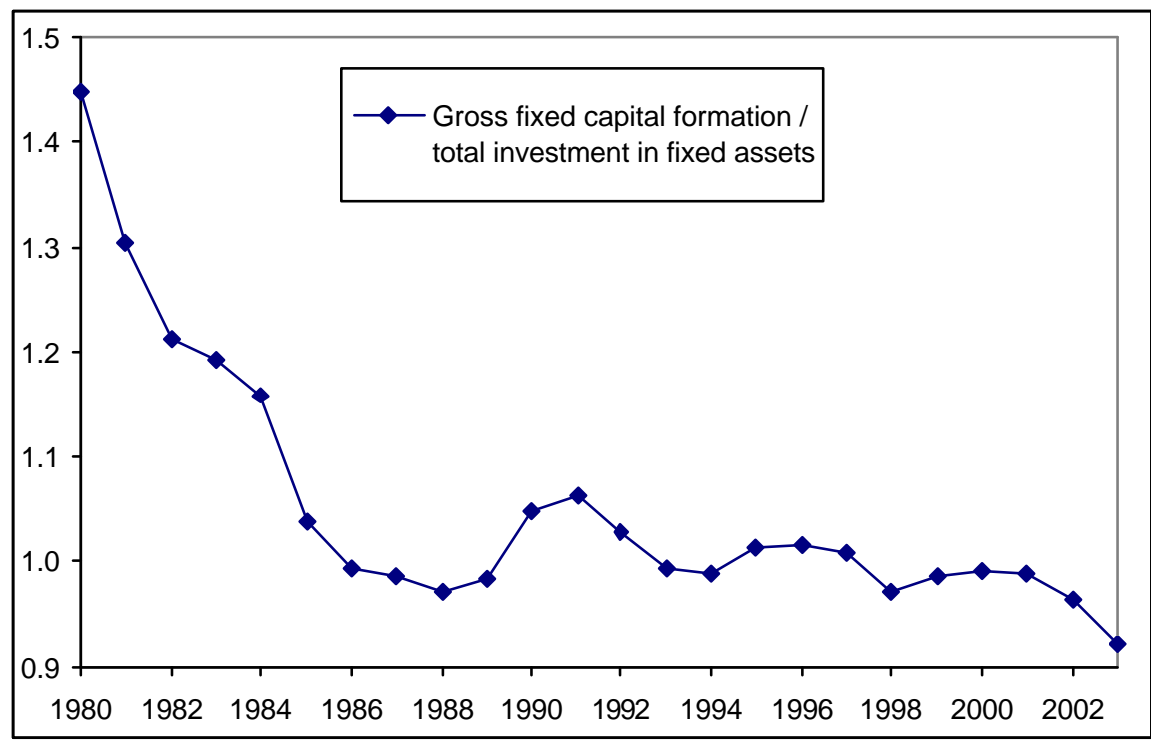

Sources: gross fixed capital formation: GDP 1952-1995, p. 50, Statistical Yearbook 2004, p. 66; total investment in fixed assets: Investment 1950-2000, p. 15, Statistical Yearbook 2004, p. 188.

Figure 1. Gross Fixed Capital Formation vs. Total Investment in Fixed Assets 
Table 5. Summary Table on Effective Investment, Scrap Rates, Transfer Rates

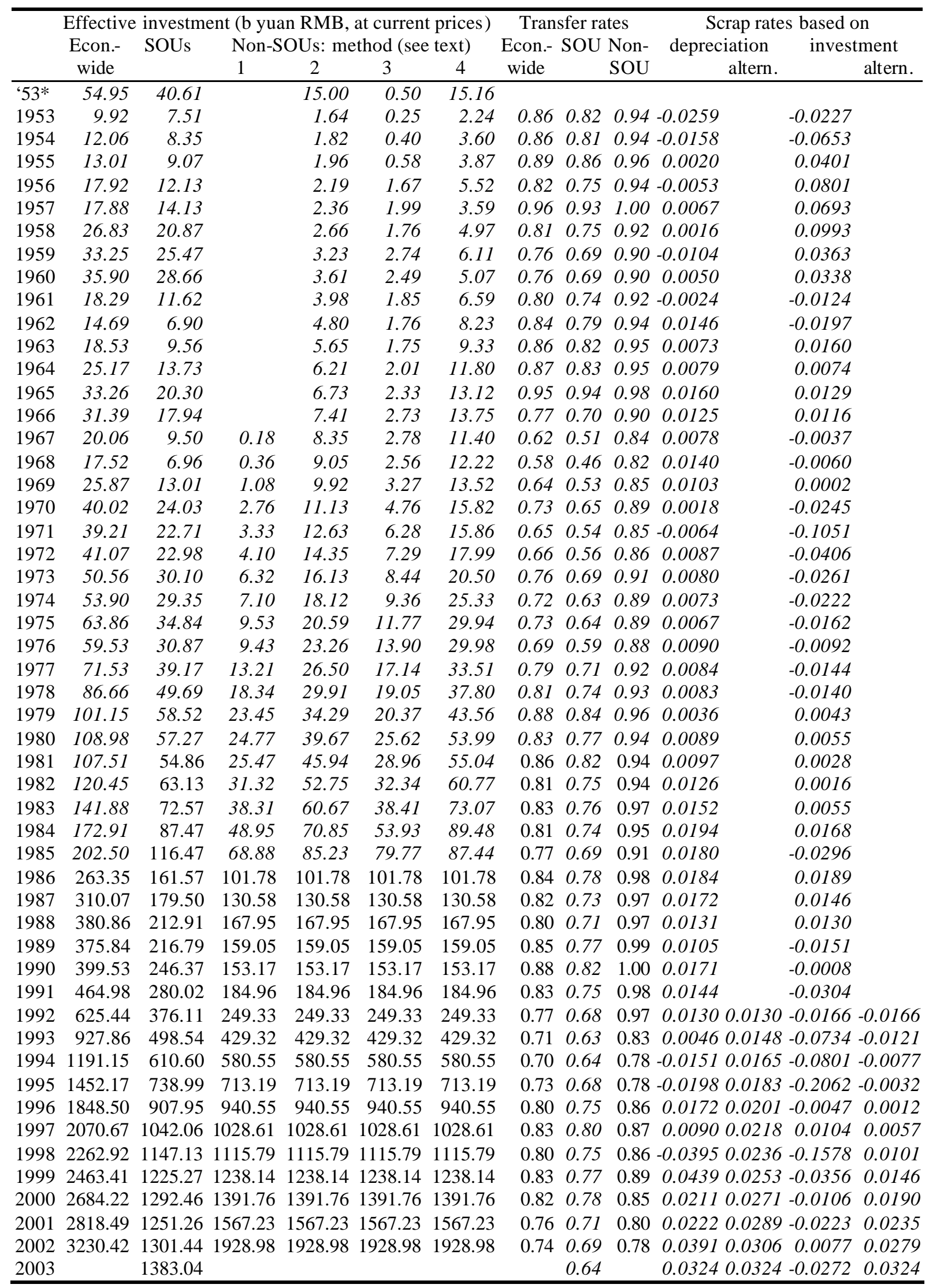

* Values in line "' 53*" are obtained using perpetual investment method (sum 49-53 for non-SOUs, method 3).

Values in italics are estimated values. Transfer rates economy -wide and of non-SOUs are estimated through 1980. Depreciation-based scrap rates are those of budgetary SOEs in 1952-92 and those of industrial SOEs otherwise, investment-based scrap rates are those of SOUs in 1966-74, and those of industrial SOEs otherwise; for a statistical break in 1998 and the inconsistency of investment-based scrap rates after 1997 see the text.

For details and sources see appendix on investment data and appendix on scrap rates. 
Table 6. Estimates of Fixed Asset Values in 1992 (end-year, in b yuan RMB)

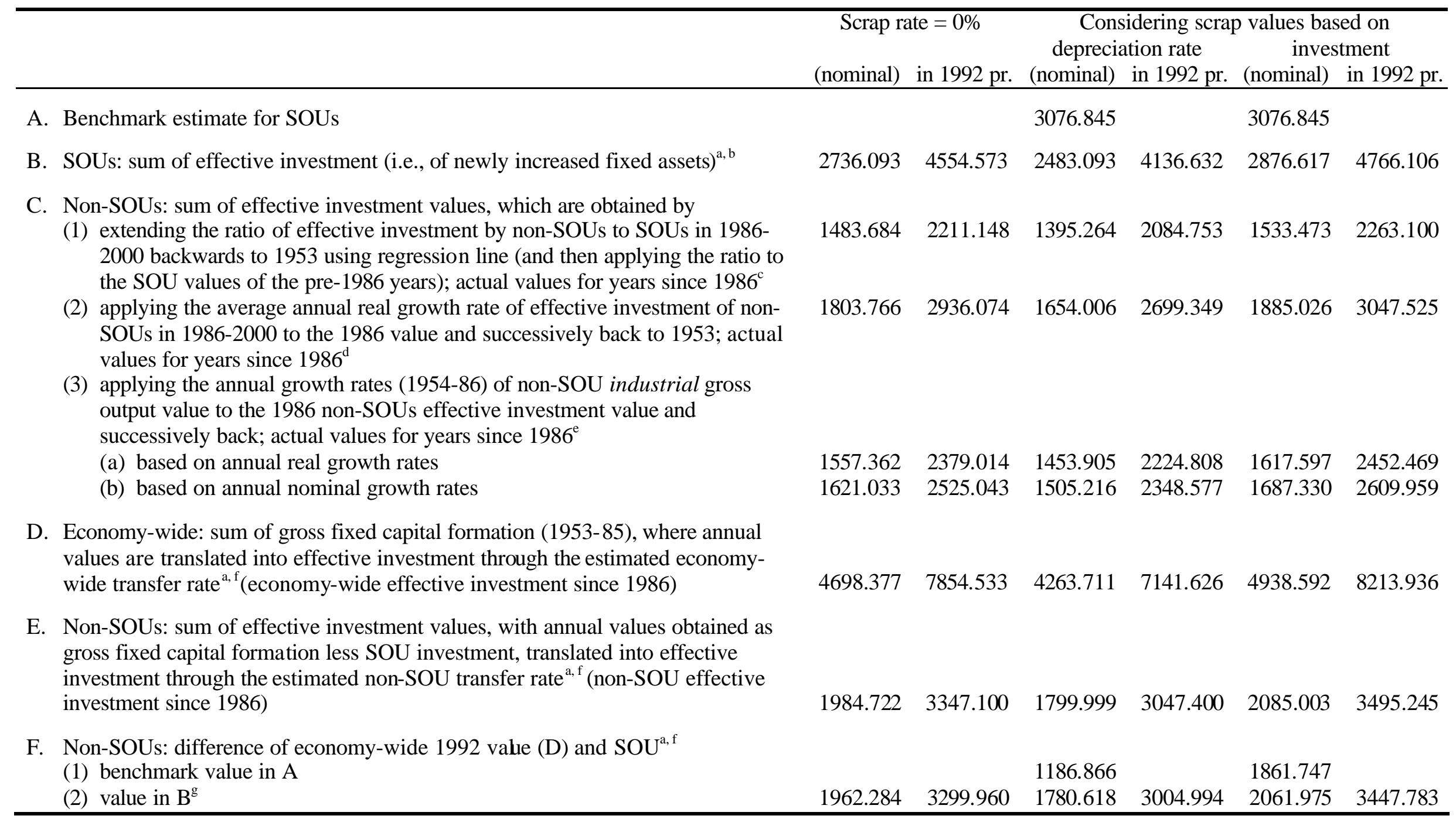


a First-year effective investment values (of 1953) are augmented by an estimate of earlier investment values through the perpetual method. I.e., 1953 effective investment data are multiplied by " $1+\mathrm{g}$ " and divided by "g," where $\mathrm{g}$ is the average annual growth rate of (nominal) effective investment between 1953 and 1958 (real growth in line C.2). It makes little difference whether nominal or real growth rates are used since the deflator shows little variation in the mid 1950s; pre-1953 annual scrap rates are assumed to be zero (the data of the later years might suggest an approximately $1 \%$ scrap rate based on depreciation rates, or just below zero based on investment data); the augmented 1953 value of, now, original value of fixed assets, is deflated in full at the 1953 level since no deflators for earlier years are available. (The use of a 5-year growth rate follows Alwyn Young's (2003) practice.)

b Data for the years prior to 1980 are the sum of capital construction and (estimated) technological updating and transformation effective investment. In 1980, the available data point on technological updating and transformation excludes "other" SOU investment (included in the data on technological updating and transformation in prior years, and therefore included in the estimated technological updating and transformation effective investment). In 1980, the transfer rate based on capital construction and technological updating and transformation is applied to total SOU investment to obtain the value of effective investment by SOUs. Data for the years after 1980 are official data on effective investment by SOUs.

c The regression line in C. 1 is ratio $=-62.4947+0.0318 *$ year (both coefficients significant below $0.005 \%$ level). The values start in 1967 , the first year with a positive ratio.

d The average annual real growth rate in C.2 is $12.24 \%$. Values for 1953 are augmented by $(1+\mathrm{g}) / \mathrm{g}$, where $\mathrm{g}$ is the average annual real growth rate.

e Growth rates in C.3 are year-specific. For example, dividing the 1986 value of non-SOU effective investment by one plus the 1986 real growth rate of non-SOU gross output value yields an estimate of 1985 effective investment; applying the 1985 growth rate to this value yields a 1984 estimate of effective investment, etc. Gross output values go back to 1949; the sum of the 1949-53 values are treated as 1953 value.

f Actual transfer rates are used (based on official data on investment and effective investment) for years 1981-85.

g One might expect the data in E and in F.2 to be identical but they are not, for two reasons. First, pre-1953 values were estimated using the perpetual investment method and the average annual growth rates of 1953-58; these average annual growth rates differ across ownership categories. (If the perpetual method is abandoned, the values in E equal those in F.2 in the first two data columns.) Second, while the scrap rate time series is identical for each row within a particular column of the table, the cumulative values to which different year-specific scrap rates are applied differ because SOU and non-SOUs have a different investment pattern over time.

The deflator throughout is the implicit deflator of gross fixed capital formation through 1990, and the investment in fixed assets price index thereafter. The same table as the one above but with a variety of transfer rates for cases D, E, and F is provided in an appendix on fixed asset data. The choice of transfer rate for the years prior to 1981 has only a minor impact on results.

Sources (see appendices on investment data, scrap rates, and fixed asset data for detailed sources):

Benchmark estimate for SOUs: see text.

Effective investment (newly increased fixed assets): SOUs: see Table 5.

Gross output values, nominal and real: Industrial Yearbook 1993, pp. 34f., with real growth rates only available for total gross output value (and the implicit deflator then applied to all individual ownership categories).

Gross fixed capital formation, nominal and real: GDP 1952-95, pp. 50f.

Transfer rates: see Table 5 .

Scrap rates: see Table 5. 
Table 7. Economy-wide Midyear Fixed Asset Values (b yuan year 2000 RMB)

\begin{tabular}{|c|c|c|c|c|c|c|}
\hline \multirow{3}{*}{$\begin{array}{l}\text { Calculation } \\
\text { method for: } \\
\text { SOUs } \\
\text { Non-SOUs }\end{array}$} & \multicolumn{2}{|c|}{ Scrap rate $=$} & \multicolumn{2}{|c|}{$\begin{array}{l}\text { Scrap rate derived } \\
\text { from depreciation }\end{array}$} & \multicolumn{2}{|c|}{$\begin{array}{c}\text { Scrap rate derived from } \\
\text { investment }\end{array}$} \\
\hline & $B$ & $B$ & $B$ & economy- & $B$ & B augm. \\
\hline & C. 3 & C.3 & $E$ & wide & C.3 & C.3 augm. \\
\hline 1954 & 170.365 & 169.591 & 232.920 & 230.046 & 175.419 & 206.012 \\
\hline 1955 & 205.831 & 203.310 & 282.284 & 279.717 & 211.792 & 248.727 \\
\hline 1956 & 252.044 & 247.394 & 343.150 & 341.259 & 244.367 & 286.983 \\
\hline 1957 & 312.494 & 305.207 & 413.965 & 412.945 & 285.467 & 335.251 \\
\hline 1958 & 392.182 & 381.624 & 501.779 & 503.130 & 338.905 & 398.008 \\
\hline 1959 & 492.119 & 477.705 & 617.093 & 623.658 & 415.905 & 488.436 \\
\hline 1960 & 604.808 & 585.741 & 742.191 & 756.042 & 514.343 & 604.042 \\
\hline 1961 & 690.116 & 665.250 & 840.863 & 859.004 & 595.478 & 699.326 \\
\hline 1962 & 731.818 & 700.534 & 898.412 & 915.821 & 646.481 & 759.223 \\
\hline 1963 & 766.889 & 729.225 & 949.246 & 965.082 & 682.535 & 801.565 \\
\hline 1964 & 813.994 & 769.745 & 1020.051 & 1034.548 & 722.493 & 848.492 \\
\hline 1965 & 882.758 & 831.324 & 1113.938 & 1127.378 & 784.296 & 921.072 \\
\hline 1966 & 962.174 & 902.732 & 1218.082 & 1230.507 & 854.458 & 1003.470 \\
\hline 1967 & 1023.142 & 954.911 & 1303.412 & 1313.617 & 912.380 & 1071.494 \\
\hline 1968 & 1064.004 & 986.310 & 1364.389 & 1369.789 & 957.698 & 1124.715 \\
\hline 1969 & 1114.070 & 1026.312 & 1436.088 & 1436.963 & 1010.491 & 1186.715 \\
\hline 1970 & 1202.299 & 1103.956 & 1557.209 & 1557.117 & 1111.824 & 1305.719 \\
\hline 1971 & 4.798 & 1205.157 & 1713.883 & & 1300.878 & 1527.744 \\
\hline 1972 & 3.833 & 1307.024 & 1864.418 & 1867.299 & 1507.161 & 1770.000 \\
\hline 1973 & 1560.365 & 1425.456 & 2023.785 & 2026.769 & 1688.495 & 1982.958 \\
\hline 1974 & 7.876 & 1558.699 & 2209.277 & 2210.687 & 1876.695 & 2203.979 \\
\hline 1975 & 99.609 & 1704.939 & 2420.330 & 2418.529 & 2074.008 & 2435.702 \\
\hline 1976 & 2041.316 & 1859.848 & 2637.490 & 2631.517 & 2271.334 & 2667.441 \\
\hline 1977 & 2229.051 & 2029.433 & 2863.161 & 2852.650 & 2485.439 & 2918.885 \\
\hline 1978 & 2459.089 & 2239.823 & 3134.603 & 3120.543 & 2749.608 & 3229.123 \\
\hline 1979 & 6.955 & 2486.233 & 3460.781 & 443.618 & 3029.126 & 3557.387 \\
\hline 1980 & 3013.151 & 2749.123 & 3817.289 & 3794.595 & 3301.316 & 3877.045 \\
\hline 1981 & 9.200 & 3010.024 & 4164.166 & 552 & 3574.954 & 4198.405 \\
\hline 1982 & 8.401 & 328 & & & .181 & 4541.595 \\
\hline 1983 & 3934.849 & 3589.606 & 96.129 & 4844.962 & 4191.373 & 4922.323 \\
\hline 1984 & 4332.634 & 3956.292 & 5331.283 & 5268.621 & 4548.309 & 5341.507 \\
\hline & & & & & & 1.314 \\
\hline 1986 & 301 & 5031.834 & 73 & 4.707 & .765 & 6671.331 \\
\hline 1987 & 6233.974 & 5750.490 & 7056.434 & 6986.575 & 6417.825 & 7343.418 \\
\hline & 6.876 & & & & & 8103.096 \\
\hline 1989 & & 7322.9 & & & .676 & 8937.596 \\
\hline 1990 & 8683.975 & 8063.517 & 89.486 & 9221.507 & 8851.721 & 9772.932 \\
\hline 1991 & 9502.488 & 8829.038 & 10015.124 & 9947.749 & 9761.820 & 10690.486 \\
\hline & & & & & & 54.221 \\
\hline 1993 & 4.692 & 10705.463 & 9.315 & 11772.780 & 11966.836 & 12911.923 \\
\hline 1994 & 31.602 & 11899.886 & 9.037 & 2.857 & 13271.268 & 14219.635 \\
\hline & & & & & & 15698.618 \\
\hline 1996 & 4 & 55 & 37 & 89 & .326 & 17421.684 \\
\hline 1997 & 183 & 9.476 & 5.488 & 0.428 & .663 & 19372.042 \\
\hline 1998 & 54.965 & 06.684 & 50.985 & 19596.333 & 20512.538 & 21459.687 \\
\hline 1999 & & & & & 22731.288 & 23674.968 \\
\hline 2000 & 5.911 & & & & .903 & 25996.943 \\
\hline 2001 & 72.650 & 35.960 & 26242.711 & 26179.401 & 27427.441 & 28360.751 \\
\hline 2002 & 30781.843 & 29001.018 & 28697.085 & 28634.251 & 29922.827 & 30849.374 \\
\hline \multicolumn{7}{|c|}{ annual growth rate (in \%) } \\
\hline & 1140 & 11.10 & 10. & 10.94 & 11.47 & 11.47 \\
\hline 1954-1999 & 11.46 & 11.32 & 10.61 & 10.63 & 11.42 & 11.12 \\
\hline & 11.46 & 11.33 & 10.60 & 10.62 & 11.39 & 11.09 \\
\hline & 11.4 & 11.31 & 10.55 & 10.57 & 11.30 & 11.00 \\
\hline 1978-1999 & 11.10 & 11.29 & 9.66 & 9.67 & 10.58 & 9.95 \\
\hline $1978-2000$ & 11.12 & 11.30 & 9.69 & 9.69 & 10.57 & 9.94 \\
\hline 1978-2002 & 11.10 & 11.26 & 9.67 & 9.68 & 10.46 & 9.86 \\
\hline
\end{tabular}

For the abbreviations B, C.3, E, see Table 6. "Augm." = augmented as explained in text. 


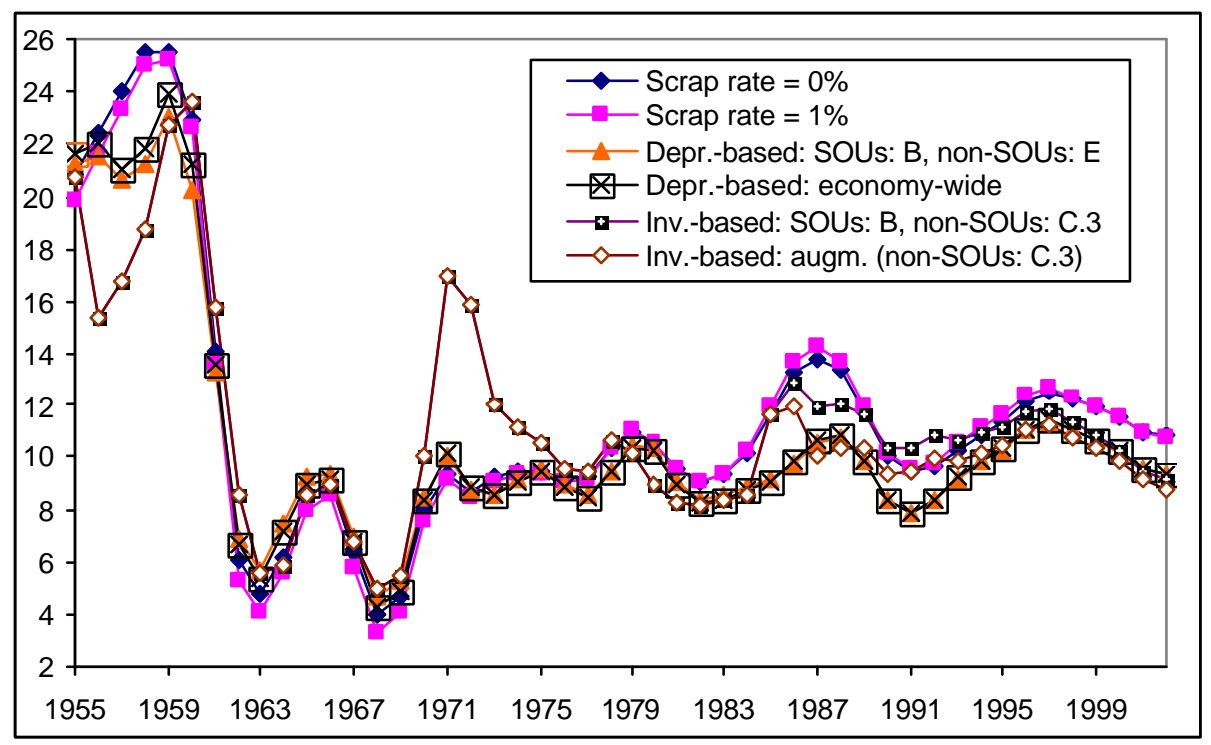

Growth rates are annual real growth rates in percent.

Figure 2. Growth Rates of Economy-wide Fixed Asset Values, Cumulative Approach, 1955-2002

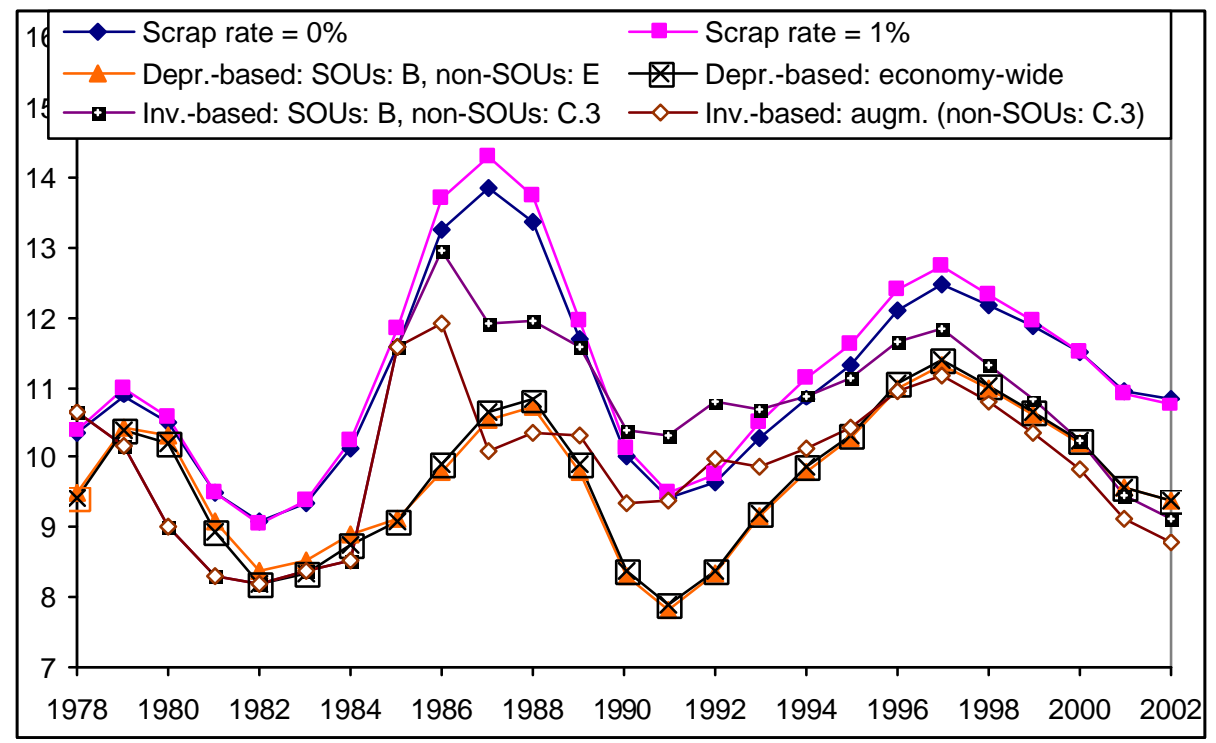

Growth rates are annual real growth rates in percent.

Figure 3. Growth Rates of Economy-wide Fixed Asset Values, Cumulative Approach, 1978-2002 


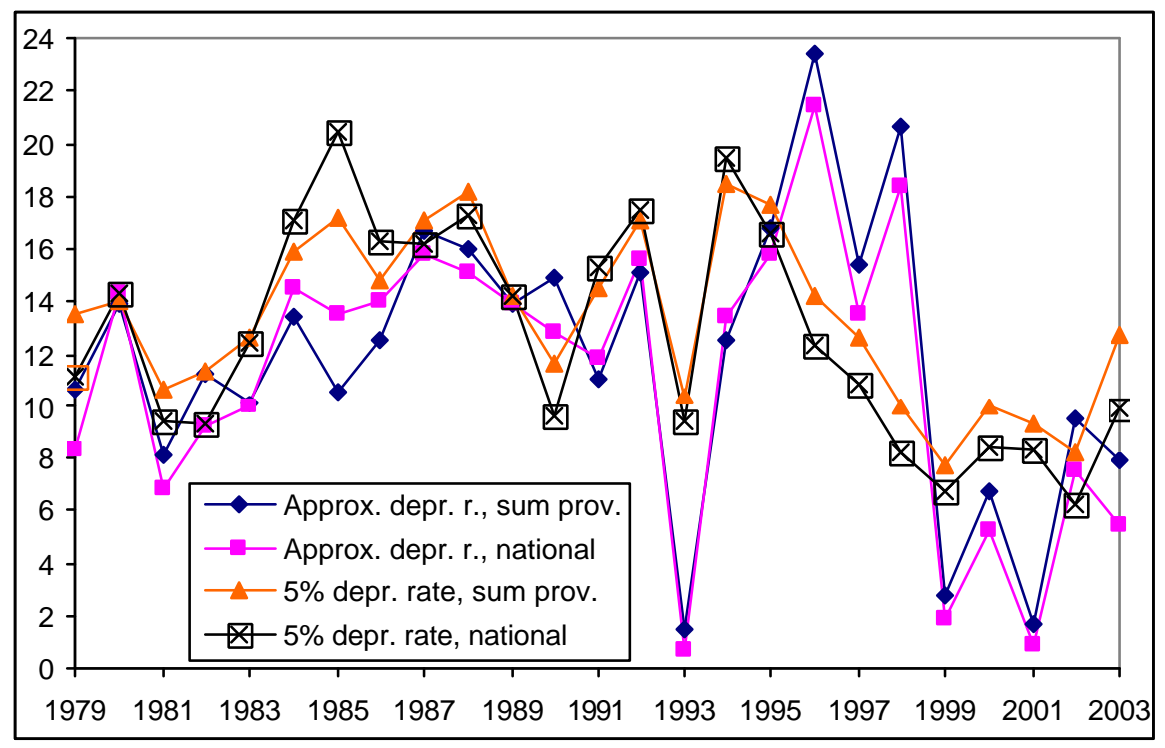

Growth rates are annual real growth rates in percent. The underlying fixed asset data (in the NIA approach) are calculated under the assumption of a $1 \%$ scrap rate.

Figure 4. Growth Rates of Economy-wide Fixed Asset Values, NIA Approach

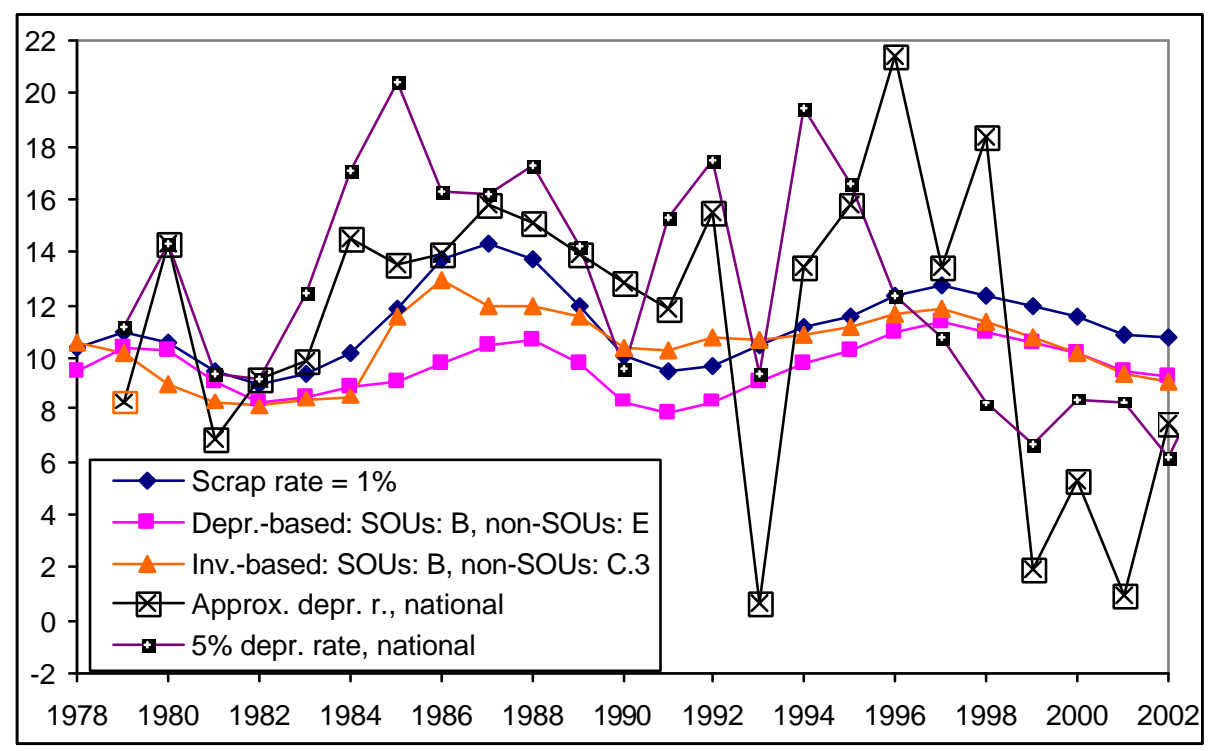

Growth rates are annual real growth rates in percent. The underlying fixed asset data of the fourth and fifth series (NIA approach) are calculated under the assumption of a 1\% scrap rate.

Figure 5. Growth Rates of Economy-wide Fixed Asset Values, Cumulative vs. NIA Approach 


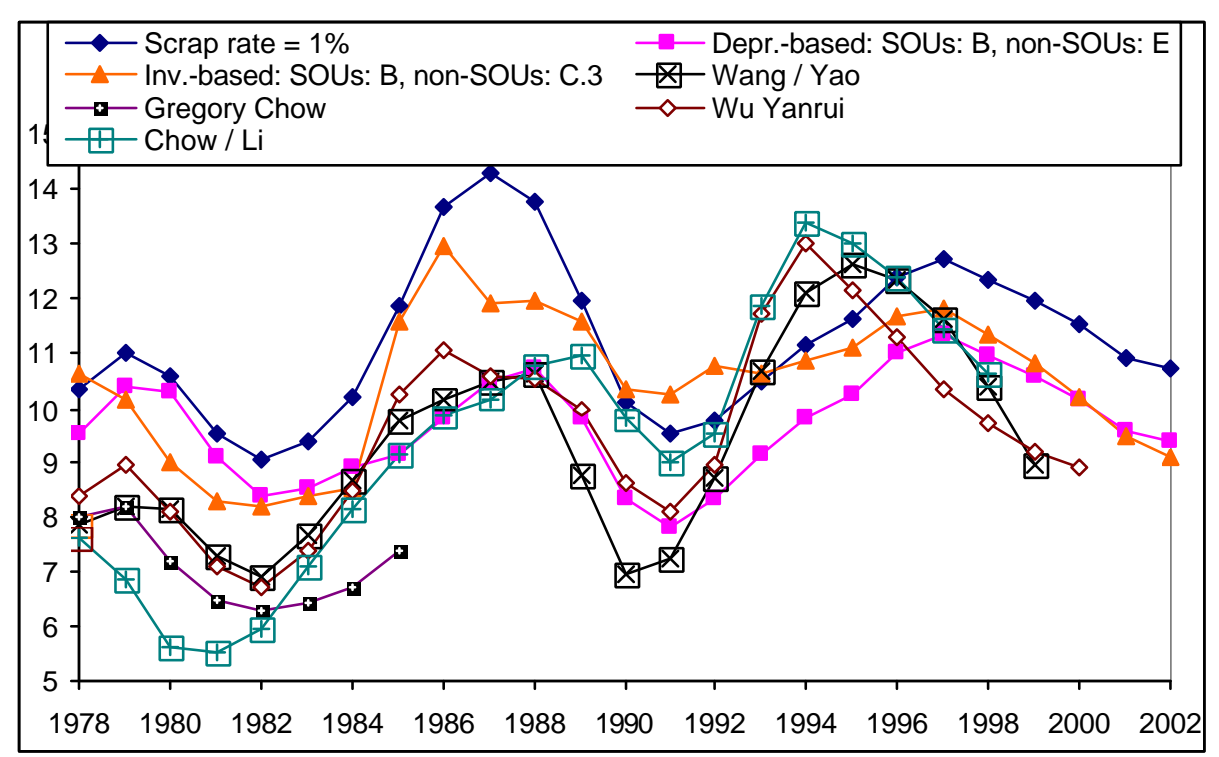

Values are annual real growth rates in percent.

Wang Yan and Yao Yudong's series is based on cumulative gross fixed capital formation and a "depreciation rate" of 5\%; for the end-year data see Wang Yan and Yao Yudong (2003), pp. 49f. Wu Yanrui's data are based on a 7\% depreciation rate; for the end-year data see Wu Yanrui (2004), p. 115. For Gregory Chow's end-year data see Gregory Chow (1994), p. 203 (sum fixed capital stock across five material production sectors) and for the Chow / Li data Gregory Chow and Kui-Wai Li (2002), p. 250; also see the discussion of the latter two datasets data in an appendix on Gregory Chow and Chow/Li. For comparison purposes, the end-year fixed asset values in all four sources were turned into midyear values.

\section{Figure 6. Growth Rates of Economy-wide Fixed Asset Values, Comparison with Time} Series in the Literature

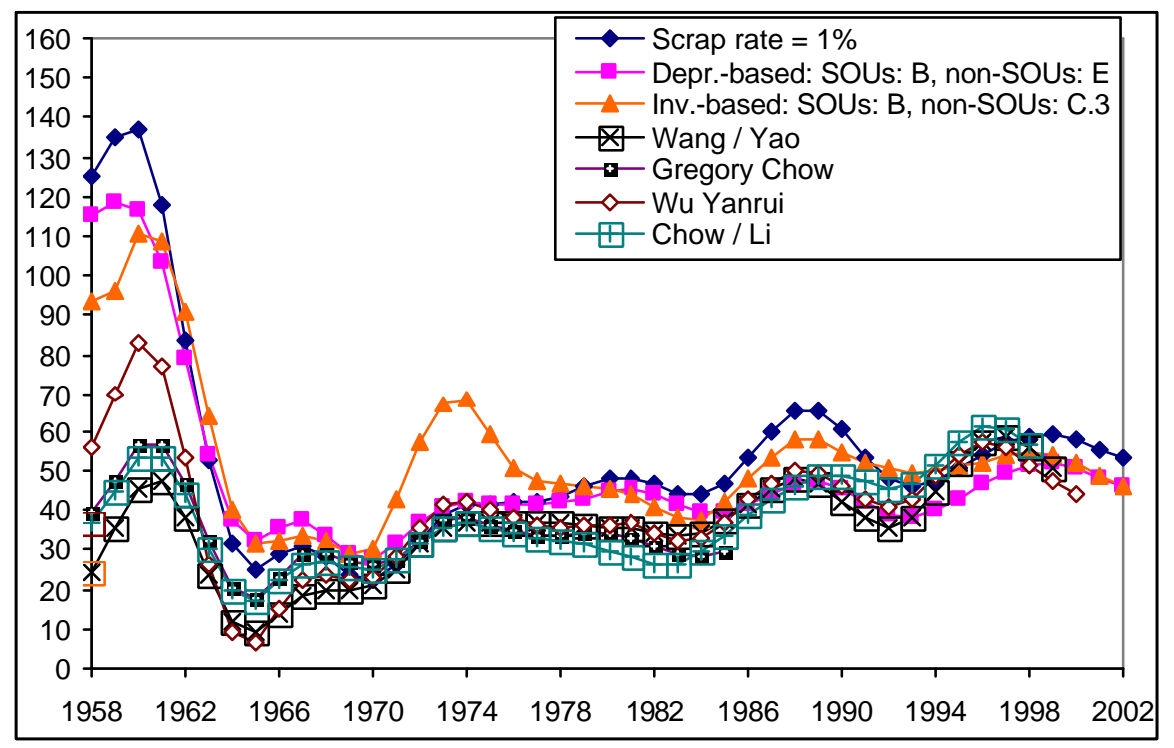

Four-year growth refers to the aggregate real growth over the previous 4 years, in percent.

For explanation/ sources of Wang/Yao, Gregory Chow, Wu Yanrui, and Chow/Li see Figure 6.

Figure 7. Four-Year Growth in Economy-wide Fixed Asset Values, 1958-2002 


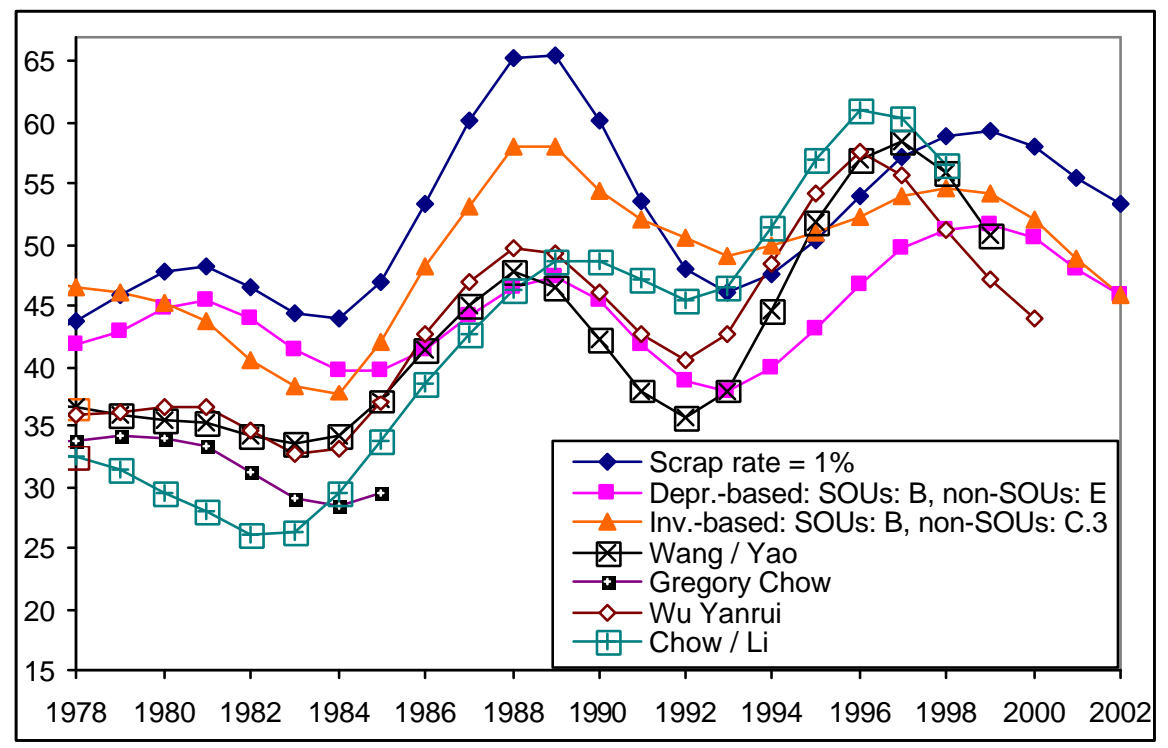

Four-year growth refers to the aggregate real growth over the previous 4 years, in percent.

For explanation/ sources of Wang/Yao, Gregory Chow, Wu Yanrui, and Chow/Li see Figure 6.

\section{Figure 8. Four-Year Growth in Economy-wide Fixed Asset Values, 1978-2002}

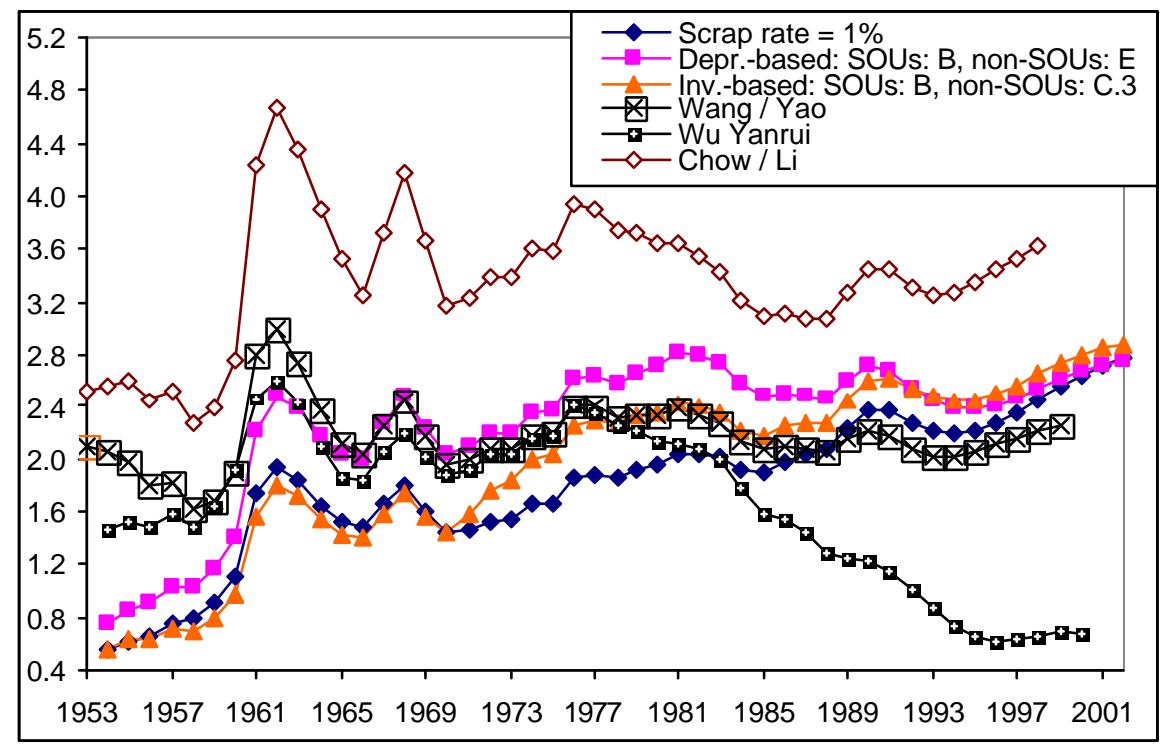

Fixed assets and GDP series are in constant prices.

Sources: Wang Yan and Yao Yudong (2003), pp. 49f., for their real capital stock and real GDP series (in 1995 constant prices); Wu Yanrui (2004), pp. 115, 121 (“K0" and "GDP0," both in billion 1952 values); Gregory Chow and Kui-Wai Li (2002), p. 250; otherwise see above for fixed asset series, with GDP data from Statistical Yearbook 2004, pp. 53 (nominal 2000 value) and p. 56 (real growth since 1979), GDP 1952-95, p. 36 (real growth 1953-1995, with identical data as the Statistical Yearbook for the years since 1979).

\section{Figure 9. Value of Fixed Assets Per Unit of GDP}




\section{Notes}

1 See, for example, Gregory Chow and Li Kui-Wai (2002), Alwyn Young (2003), Wang Yan and Yao Yudong (2003), or Wu Yanrui (2004). Gregory Chow (1994) uses a depreciation rate of zero.

2 See, for example, Chen Kuan et al. (1988) or Gary Jefferson et al. (1992, 1996, 2000).

3 See, for example, Finance Ministry (1999), Vol. 1, p. 438, for the case of industry. The fourth item is a net item, i.e., unresolved losses on fixed assets less gains on fixed assets; this item comes from the account "unresolved losses or gains on fixed assets" (dai chuli guding zichan sunyi) (p. 430). Actual data following this breakdown of fixed assets are available for collective-owned township and village enterprises (xiangzhen jiti qiye). In 2002, net fixed assets accounted for $90.69 \%$ of their fixed assets, corrections to fixed assets for $0.33 \%$, fixed assets under construction for $8.83 \%$, and unresolved net losses on fixed assets for $0.15 \%$. Cumulative depreciation was equivalent to $39.12 \%$ of net fixed assets, and the original value of fixed assets was indeed $139.12 \%$ of the net fixed asset value. (TVE Yearbook 2003, pp. 229f.)

Entries in the account "corrections to fixed assets" cover fixed assets that are no longer included in the account "original value of fixed assets." The corrections have not yet been finalized in the sense that the fixed asset is, for example, in the process of being sold or decommissioned (and is no longer in use), but the transaction has not yet been completed. The same applies to "unresolved net losses on fixed assets."

The value of depreciation and, thus, net fixed assets, furthermore, is determined by political decisions, tax considerations, competition, the speed of innovation and other factors. Do these have any impact on the contribution of buildings and machinery actually in use to the creation of output?

6 One possible further complication is that the term "productive" appears to refer to production under the planned economy's Material Product System (MPS). In the MPS, only agriculture, industry, construction, communication (transportation), and commerce are productive; most of the tertiary sector, such as health services (hospitals), education, or scientific research are regarded as unproductive. (Some components of the tertiary sector, such as agricultural services and geological prospecting, are likely to be included in the productive MPS components agriculture and industry.)

The output value of (imputed rent on) housing is approximately $2 \%$ of the "value" of housing in rural areas, and $4 \%$ of the "construction costs" of housing in urban areas (Xu Xianchun 2000, pp. 51f.). NBS (1997), p. 100, uses $2-4 \%$ of the original housing value without distinction between rural and urban areas. For details on the valuation of housing in the GDP calculation see Carsten Holz (2004).

8 The issue of revaluation first arose in 1990. By 1992, a central leading group was handling first trials. The qingchan hezi campaign, here translated as revaluation, not only concerns the (positive) revaluation of fixed assets but also clarification of ownership rights, properly cleaning up past losses hidden in balance sheets, accounting for asset stripping, and other issues related to assets. In the early phase, the revaluation of fixed assets appears to have played only a very minor role, but starting in 1993, when the policy was applied to SOEs nationwide, became more prominent. Rural collectives were asked to revalue their fixed assets in 1995, urban collectives in 1996. Several hundred regulations over the years cover or mention revaluation. The key regulations were issued by the State Council in 1993 (SC 3 May 1993, and the implementing instructions SC 14 May 1993). The Finance Ministry five years later, on 21 Sept. 1998, issued a detailed regulation for "day-today" use (in contrast to the campaigns of the early and mid-1990s).

9 A further complication could be that the fixed asset data reflect the stock of (available) fixed assets rather than the utilization of fixed assets in production. Utilization of the stock of fixed assets is likely to vary over time, such as during the different phases of the business cycle. Adjustments of capital stock values for capacity utilization may be meaningful in production function estimations. Economy -wide (or sectoral, or ownership group) utilization data are to my knowledge not available. The 1995 industrial census provides some utilization data by industrial sub-sectors.

10 For details on the availability of fixed asset data see the appendix on fixed asset data. This appendix, as all other appendices mentioned below, is available at http://[omitted], without the website reference being repeated every time. Appendices also provide detailed data sources, information too lengthy to always include in full in the paper. (The main sources of numerical data throughout are the Statistical Yearbook, Fiscal Yearbook, GDP 1952-95, Industrial Yearbook, Investment 1950-2000, Investment Materials 1950-85, and the Investment Yearbook.)

11 Budgetary SOEs refers to those SOEs included in the budget; for further details see the appendix on fixed asset data. The table in the Statistical Yearbook reporting these depreciation rates does not come with any note to the effect that they are only applicable to budgetary SOEs. However, the depreciation rate table immediately follows two tables on original and net fixed asset values which also do not carry such a note but only cover budgetary SOEs as revealed by a countercheck with identical data in the Fiscal Yearbook. (Except for one 
further table, on fixed-quota working capital, all other tables in this Statistical Yearbook section are not related to fixed assets.)

12 "Directly reporting industrial enterprises" prior to 1998 denotes industrial enterprises with independent accounting system at township level and above, and since 1998 all industrial SOEs plus industrial non-SOEs with independent accounting system and annual sales revenue in excess of 5m yuan RMB; these enterprises report regularly and directly to the statistical authority.

13 The only province for which both end-year and midyear fixed asset values are available, Shaanxi, has an economy -wide depreciation rate of $4.86 \%$ based on end-year original fixed assets and of $5.29 \%$ based on midyear original fixed assets. The depreciation rate of industrial SOEs in Shaanxi in 2000 is $4.91 \%, 0.38$ percentage points less.

14 Data on one province only (Shaanxi), for one year only, which suggest the need to increase the depreciation rates of industrial SOEs by 0.38 percentage points to reach the economy -wide level, appear too little to make full adjustments of national data. But an upward adjustment to national data of 0.01 percentage points in 2001 and 2002 to raise a rounded 5.14 and 5.04 to 5.2 and 5.1 seems plausible.

15 Production and income approach GDP calculations are not conducted entirely separately; the production approach makes use of some income approach data. See Carsten Holz (2002) for details. The in most years perfect equality of production and income approach data for most provinces suggests that one component of the income approach may have been derived as residual.

16 The discrepancy between the sum of provincial value-added and national GDP is highest in 2003, when the provincial figure is $15.60 \%$ higher. The reverse is true for some of the earlier years, when comparing the sum across provinces (as first published since 1996, with revised figures not available, and possible representing revised data for the years prior to 1996) to revised national data (no first published data are available for the years through 1988).

A rate of 5\% is used by, for example, Wang Yan and Yao Yudong (2003), who in turn cite other authors to justify this choice. Alwyn Young (2003) assumes a 6\% depreciation rate, and Wu Yanrui (2004) a 7\% depreciation rate.

18 For a full discussion of the two deflators and alternatives see the appendix on the selection of the investment in fixed asset deflator. Gregory Chow (1994), p. 199, in the construction of his capital series assumes "that the price index for accumulation goods between 1952 and 1983 remained constant." Table 1 shows that the cumulative deflator for gross fixed capital formation is indeed only about 12\% higher in 1983 than in 1952; however, this ignores significant fluctuations in the $1950 \mathrm{~s}$ and $60 \mathrm{~s}$ which matter if accumulation data are added up (they should be deflated using the year-specific cumulative deflator).

19 For example, in the case of the approximate depreciation rate applied to the sum of depreciation across provinces, the deflated 1978 value is the original nominal value of 902.541 b yuan RMB in Table 3 divided by the cumulative deflator of 0.2725 , i.e. 3312.526 b yuan constant year-2000 RMB in Table 4 (with more decimals used in the calculations than reported). The 1979 increment of, continuing with the same example, 991.553 less 902.541 (Table 3), i.e., 89.012, is deflated by the 1979 cumulative deflator of 0.2783 (Table 4 ) and then added to the deflated $1978 \mathrm{v}$ alue of $3312.526 \mathrm{~b}$ yuan RMB to yield 1979 economy -wide fixed assets in year 2000 constant prices of 3632.333 b yuan RMB (Table 4).

20 Depreciation values based on national GDP as first published are not included because these values only start in 1989. Deflating the complete 1989 value using the 1989 cumulative deflator seems not justifiable given the steep upward trend of the deflator in the previous years (Table 1). (One could obviously combine this series with one of the other ones for the years prior to 1989.) In contrast, deflating the complete 1978 value using the 1978 cumulative deflator appears justified in that prices over the previous ten years changed little (Table 1). Even if the cumulative deflator were not fully applicable to all 1978 fixed assets, the impact on later-year values is extremely small; the deflated 1978 fixed assets account for only one-eighteenth to one-twelfth of the year 2000 value.

21 See, for example, the 1992 accounting regulations for industry in Finance Ministry (1999), Vol. 1, p. 428. Accounting regulations are sector-specific. All references to accounting regulations below refer to industry. Any Western university textbook on accounting will equally well do.

22 See Finance Ministry (1999), Vol. 1, p. 453.

23 The term "scrap value" is used here to denote the original purchasing price of the fixed asset that is decommissioned (which is needed for equation 2 to be correct); it does not denote some residual market or book value. If this definition of "scrap value" were misleading, another label could be used.

With data on scrap values not published - the aggregate scrap value is not a variable of relevance in the accounting system - an immediate check of the equation via data is not possible. The accounting regulations, while not explicitly listing this (or any other) equation, describe equation (2) with all three right-hand side variables in text form (Finance Ministry, 1999, Vol. 1, p. 428). At the enterprise rather than economy-wide level, 
the equation should be expanded to include such items as leased equipment and equipment received without compensatory payment.

24 In their equation, depreciation allowance comes with a negative sign, which I take to be a typo and corrected here. The same equation (with all variables in constant prices) can be found in Gary Jefferson et al. $(1992,1996)$, but with the correct sign for the depreciation allowance.

25 Chen Kuan et al. (1988) provide two equations (p. 244). In their first equation, current-year "fixed assets at original costs" equal previous-year fixed assets at original cost plus investment. This is incorrect in that the value of decommissioned fixed assets needs to be subtracted for the equation to hold (apart from the fact that they ignore revaluations).

26 For example, Gary Jefferson et al. (2000) report that "a completely unexpected outcome is the dramatic TFP [total factor productivity, or efficiency] decline of 7.96\% in the shareholding sector during 1993-1996" (p. 798). The authors do not report their underlying data; it would not be astonishing if the (ignored) revaluations of fixed assets and thereby their artificially inflated "net investment" led to a sharp increase in capital relative to output, which in turn lowers TFP growth.

27 The scrap rate could also be expressed as the ratio of deflated scrap values to deflated original values of fixed assets. Price variations then do not contribute to scrap rate variations across years. Given that scrap rates are never constant across years (since investment growth rates vary over time), there seems to be nothing to gain from a scrap rate based on deflated data; it only complicates calculations further.

28 See Finance Ministry (1999), Vol. 1, pp. 428, 453.

29 See a circular by the Finance Ministry (21 Sept. 1992) for these procedures.

30 The value of net fixed assets is affected if the fixed asset has not been fully written off at the time it is decommissioned, but this is different from the regular decommissioning of fixed assets that are no longer used. The equations here omit special circumstances such as the sale of a fixed asset that has not been fully written off. 31 See Finance Ministry (1999), Vol. 1, pp. 409f., with two dozen asset-specific depreciation periods on p. 416. 32 For details on the shortcomings of the investment data see the appendix on investment data.

33 For the three items to be deducted, they must have been included in one of the four components of gross fixed capital formation in the first place. Presumably this is total society investment in fixed assets, but the source refers to total society investment in fixed assets only for item b ("other items in other costs"). The source provides further details on components (i) and (ii).

Investment in fixed assets by the definition of fixed assets in the accounting system excludes the value of land because land is an intangible asset (a separate asset category). However, the investment statistics of the NBS need not necessarily adhere to accounting definitions. If the purchase of old structures, old equipment, and land were included in the investment statistics, they are likely to have been of rather minor size before the 1990s. The "effective investment" data used here to derive fixed asset values should net out these purchases at all times. In addition, if industry is representative of the whole economy, the use of investment-based scrap rates below in the derivation of fixed asset values corrects for any remaining mis -estimation of investment. For further discussion of these issues see the appendix on investment data.

34 In 1980, gross fixed capital formation accounted for $28.96 \%$ of expenditure approach GDP. A $44.69 \%$ overestimate of gross fixed capital formation implies a $12.94 \%$ overestimate of expenditure approach GDP. In 1980 expenditure approach GDP was equal to $100.74 \%$ of production approach GDP. (Statistical Yearbook 2004 , pp. 53, 65f.)

35 The measure used by Gregory Chow and Kui-Wai Li (2002) for the years prior to 1978 is accumulation in the Material Product System, as a component of the Material Product System's national income variable for the five material production sectors. Accumulation is also used by Gregory Chow (1994). For details, see the appendix on Gregory Chow and Chow/Li.

For details see the appendix on investment data.

37 The cumulative 1953 value is the 1953 effective investment value times $(1+\mathrm{g}) / \mathrm{g}$, where $\mathrm{g}$ denotes the average annual (nominal) growth rate of 1953-58.

38 Effective investment values would also have been available for 2001 and 2002; 2000 seemed a good year to end the regression because then the effective investment data are all from one source.

39 This assumes that SOU investment (and thereby effective investment) values prior to 1986 are rather reliable and the "culprit," if any, for the difference between gross fixed capital formation and investment (Figure 1) is the non-SOUs.

40 The reason why the perpetual method is not applied directly to the 1986 value is that scrap rates and deflator values are year-specific values. These are available starting in 1953 only. All effective investment of pre-1953 is in the derivation of fixed asset values (below) subjected to the 1953 scrap rate and deflator value. The perpetual investment method assumes that effective investment in the years prior to 1953 grew at the same 
average annual real growth rate as in the period 1986-2000. The cumulative 1953 value is the 1953 nominal effective investment value times $(1+\mathrm{g}) / \mathrm{g}$, where g denotes the average annual real growth rate of 1986-2000.

41 The gross output value series starts in 1949 and the cumulative 1953 value is the sum of the 1949-53 values. Aggregate 1949 through 1952 non-SOU effective investment is approximately equal to only $1 \%$ of 1980 nonSOU effective investment (in real terms), which renders any attempt to approximate pre -1949 effective nonSOU investment pointless.

42 The second assumption can be checked against data, which show it to be plausible. The third method is further justified by a double-check for the case of SOUs. Details are in an appendix on the output-capital ratio of non-SOUs.

43 An alternative assumption would have been that the capital-output ratios of non-SOUs is the same as that of SOUs. This assumption appears grossly unjustified when one considers that non-SOUs tend to be small and that industrial data according to enterprise size suggest a ten-fold difference in capitaloutput ratios between large and small enterprises.

44 Three possible transfer rates are the one for SOUs, estimated non-SOU transfer rates, and the mean of the two. The estimated non-SOU transfer rate used here is based on a regression of non-SOU transfer rates in 19811992 on a constant, SOU transfer rates, and the ratio of non-SOE to SOE industrial gross output value (available through 1992 only); with values on the right-hand side variables available for the years prior to 1981, the nonSOU transfer rates prior to 1981 can be estimated. For a discussion of transfer rates see the appendix on investment data. The comparison of 1992 fixed asset values provided in Table 6 below is also available in the appendix on fixed asset data, which includes values for non-SOUs based on other transfer rates than the estimated non-SOU transfer rate. (The 1953 value in the fourth method is augmented using the perpetual investment method with the nominal average annual growth rate of 1953-58.)

45 For data on all individual scrap rates and the data on which they are based see the appendix on scrap rates. The appendix also charts and discusses the scrap rate series in more detail.

46 Are these scrap rates representative of economy -wide scrap rates? In 1992, industrial SOEs accounted for slightly below one-half of SOU original fixed asset values, and SOUs for about two-thirds of the economy -wide total. If one wonders whether industrial SOEs can proxy for all SOUs, the years with overlapping scrap rates suggest a positive answer. One may suspect that rural collective-owned enterprises renew their machinery less frequently than SOUs and industrial SOEs, or that foreign-owned and domestic private enterprises renew their machinery more frequently than SOUs or industrial SOEs (but because the latter have developed rapidly only in the second half of the reform period, very little decommissioning may of yet have happened). If use of the scrap rates derived here were to lead to biased results in economy -wide circumstances, the sign of that bias is ambiguous. Given the relatively small ratio of non-SOU to SOU fixed as set values throughout most years, any bias is likely to be of small size.

47 It is possible that the data on effective investment, i.e., on newly increased fixed assets through investment are underestimates, while the investment data themselves are correct. But it is also possible, and more plausible, that investment data in the first place, and therefore also effective investment data, are (both) underestimates. The latter case is more plausible because the official data usually come in triples as investment, effective investment, and transfer rate. This suggests that investment and effective investment come as a package, not as two independent data points.

48 The point that official investment data are likely to be underestimates can also be made differently. The depreciation-based scrap values yield an implicit effective investment value if the scrap value is inserted into equation (2). This implicit effective investment value can be compared to actual effective investment. While there is a good match between the two values in the mid-1980s, in the 1950s the ratio of implicit to actual effective investment is below unity, and otherwise, as a rule, above unity, sometimes highly so. An approximately 2 percentage point lower depreciation rate would be needed to bring the average ratio down to unity; such a low depreciation rate is not plausible, which then implies that official effective investment values are likely to be too low. For further details on this double-check see the appendix on scrap rates.

49 Gary Jefferson et al. (1996, 2000) do not explain the source of their depreciation data. Gary Jefferson et al. (1992) calculate the depreciation rate as "total depreciation fund" divided by (presumably current) end-year original fixed assets. Presumably the "total depreciation fund" refers to current-year depreciation; if it referred to the cumulative depreciation account, the resulting depreciation rate would significantly exceed the actual depreciation rate.

50 If this were not clear, see equation (2), where, for the subsets of the economy examined here, fixed asset values and effective investment values were inserted; the resulting scrap values capture true scrap values plus any underestimate of the effective investment value plus revaluations. The fixed asset values for the subsets of the economy examined are likely to be highly reliable; if the investment data are not reliable, the scrap rates compensate. Using these scrap rates derived from a subset of the economy in economy -wide circumstances 
assumes that the adjustment factor of industrial SOE effective investment (and revaluation) or SOU effective investment (and revaluation) applies equally economy -wide. (In the case of non-SOUs, effective investment could be even more severely underreported in the official data, in which case even greater compensation would be necessary.)

51 See Investment Revaluation 1984-2000 for almost one thousand pages of line after line, machinery-specific price correction (inflation) factors.

52 It does so by construction, because it is derived from a subset of the economy for which original values of fixed assets incorporate (an unknown amount of) revaluations. Use of this scrap rate in the derivation of a constant price economy -wide fixed asset series implies that the resulting fixed asset series is twice pricecorrected.

53 An additional complication, ignored here, is that the 2003 scrap rate (equation 7) is based on fixed asset values (original and net, previous and current period) which incorporate past revaluations. Since all fixed asset values in this calculation incorporate past revaluations, a bias in the scrap rate, if any, is likely to be very minor. 54 The 1992 depreciation-based scrap rate in Table 5 is that of budgetary SOEs, in later years it is that of industrial SOEs. In 1992, the two values for budgetary SOEs and industrial SOEs are 0.0130 and 0.0144 which seems reasonably close to allow the cross-over from a 1992 budgetary SOE scrap rate to a 2003 industrial SOE scrap rate. The cross-over is needed due to limited data availability for budgetary SOEs. (There is a similarly close match between the two series in earlier years. The 1993 values, presumably already incorporating revaluation, for the two ownership groups are 0.0048 and 0.0046 . For the complete, individual time series see the appendix on scrap rates.)

55 The original investment-based 2003 scrap rate in Table 5 cannot be identical to the depreciation-based one because of the statistical break and inconsistent investment-based scrap rates since 1998.

56 The fixed asset series is doubly inflated, once by design, and once by mistake through the ignored revaluations.

57 To confirm that this procedure is correct, take equation (2). In the constructed nominal economy -wide fixed asset series, the absolute increase in the original value of fixed assets by definition comprises the residual "investment less scrap value" (plus revaluation). The residual "investment less scrap value" is in current-year prices; once adjusted to constant prices, it reflects the real-valued change in original fixed assets in the current period. Adding up over time yields the capital stock series in constant prices.

Viewed differently, current-year real fixed assets equal previous year's real fixed assets less real scrap value plus real investment. But real investment less real scrap value equals "current-year nominal fixed assets less previous-year nominal fixed assets, deflated to constant prices." This is what is being done in the second step: "current-year nominal fixed assets less previous-year nominal fixed assets" are deflated, and then added to the previous year's real fixed assets.

58 The 1992 SOU fixed asset value of $3076.845 \mathrm{~b}$ yuan RMB comprises the SOU original values of fixed assets in four exhaustive sectors of the economy: (i) agriculture (limited to budgetary SOEs): 70.31b yuan RMB (Statistical Yearbook 1998, p. 35 ); (ii, iii) industry and construction (all SOEs): 1566.978b and 68.44b yuan RMB (Statistical Yearbook 1993, pp. 419, 562); (iv) tertiary sector (all SOUs except those in agricultural services with fixed assets of $10.62 \mathrm{~b}$ yuan RMB, which in all likelihood are already included in agriculture): 1371.117b yuan RMB (Tertiary Sector Census 1993, pp. 618-29 and 1749-59). For further details see the appendix on fixed asset data; this appendix also provides SOU fixed asset values for other years (1980, 1981, 1982, 1991, 1995, 2000), as well as a comparison of these fixed asset values of other years with data obtained via the cumulative investment approach.

59 The non-SOU fixed asset values rely on the estimated non-SOU transfer rate to turn investment into effective investment before aggregation; the economy -wide values rely on the estimated economy -wide transfer rate. An expanded Table 6 which also uses SOU transfer rates as well as means of SOU and estimated transfer rates is available in the appendix on fixed asset data. (This also applies to lines F.1 and F.2 below.)

60 The switch to depreciation-based scrap rates causes one significant change. The value of the non-SOU residual where the SOU benchmark value (line A) is subtracted from the economy -wide value (D), now becomes the smallest value (F.1). This is due to the fact that when depreciation-based scrap rates are used, all resulting fixed asset values are smaller, and the unchanged SOU benchmark value (established as sum of dispersed fixed asset values) is now subtracted from a smaller economy -wide value.

61 With non-SOUs accounting for mo re than one-third of investment in 1986 (and one-half by 2000), the close match starting 1986 in the aggregate comparison (Figure 1) does not allow for large inaccuracies in the data on non-SOUs.

62 The individual SOU and non-SOU end-year fixed asset values for the period 1953 through 2003 in constant year 2000 billion yuan RMB are reported in the appendix on fixed asset data (and can be calculated from the data provided in Table 5 and the deflator in Table 1). 
63 Alternatively, the official data on newly increased fixed assets could be underestimates even after 1985, the benchmark values of the early 1980s could be underestimates, or the benchmark values of the early 1990s could be overestimates. For the 1980, 1981, 1982, 1991, 1992, 1995, and 2000 benchmark values see the appendix on fixed asset data.

64 The value of 0.98 is the asymptotic limit in 200 -year simulations, reached after a short start-up period when scrap rates are lower; similarly for the other lifetimes. The deflator is taken into account because the scrap rate throughout is applied to nominal values, the same way as it is derived based on depreciation or investment data. 65 Effective investment values are used throughout (in all six scenarios), in the third and fourth scenario obtained by applying transfer rates to investment data.

66 The highly negative investment-based scrap rate in 1971, for example, which causes the high growth rate in fixed assets, can be traced back to stagnant SOU investment combined with a strong increase in SOU fixed asset values (and similarly in the next few years). If depreciation rates and fixed assets values of the subset of the economy from which depreciation-based scrap rates are derived were accurate, the investment-based scrap rates of these two periods, the second half of the 1950s and the early 1970s, imply that official investment (at least in the subsets of the economy from which the investment-based scrap rates are derived) is misreported. The investment-based scrap rate then corrects for the misreporting, the depreciation-based scrap rate does not.

67 By definition, the annual growth rates of the two fixed asset series using investment-based scrap rates are identical prior to 1986 .

68 An additional issue is that non-SOU investment is subjected to the non-SOU transfer rate to obtain effective non-SOU investment; in as far as non-SOU investment in this scenario captures underreported SOU investment, that SOU investment is subjected to a higher transfer rate than it should (the non-SOU transfer rate is above that of SOUs).

69 The first, fourth, and sixth scenario are perhaps just slightly less plausible than the three discussed in more detail. A $0 \%$ scrap rate is too low in the long run, the economy-wide calculation in the fourth scenario requires economy-wide estimated transfer rates for the years prior to 1986 (rather than only for non-SOUs) and, anyway, is near-identical to the third scenario, and the augmentation in the sixth scenario assumes a constant multiplication factor for all years prior to 1986 (and the perfect accuracy of the 1992 benchmark value), assumptions which one may wish to avoid if possible.

70 NIA values in the following are national values because the values used in the cumulative approach are national values.

71 Alwyn Young (2003) does not provide year-by-year data on his economy -wide capital stock series.

72 Gregory Chow provides national income data in the Material Product System. In contrast to value-added, national income does not include depreciation and includes service payments to non-productive units (for example, interest payments). (For details see Carsten Holz and Yi-min Lin, 2001.)

73 The 1953 fixed asset values derived here for the series included in Figure 9, in 1953 prices, are 45.301, 62.219, and 46.858b yuan RMB (see values in Table 7 and deflator in Table 1; 1953 prices are at 26.7122\% of the level of year 2000 prices). In contrast, Gregory Chow (1994) has a 1952 value of 175b yuan RMB which consists of his derived 31.56b yuan RMB and 26.70b yuan RMB (total 58.26b yuan RMB) values for the fixed and the circulatory capital stock (the latter includes inventories and such items as bank deposits and accounts receivable), an assumed 45b yuan RMB in agriculture, and an assumed land value of 72b yuan RMB. For details on a number of shortcomings in Gregory Chow's calculations see the appendix on Gregory Chow and Chow/Li. Wang Yan and Ya o Yudong (2003) adopt Gregory Chow's 1952 value of 175b yuan RMB (ignoring the fact that the increments they add to this initial value exclude circulatory capital and land). Wu Yanrui (2004) uses an initial value of 95.2b yuan RMB which he adopts from another source in the literature. Gregory Chow and KuiWai Li (2002) use Gregory Chow's 1952 value augmented to 221.3b yuan RMB (ignoring the fact that the increments they add to this initial value exclude land, and that the increments include inventories but not other circulatory capital).

74 The problem with the ratios calculated from the fixed asset and GDP data in the literature could be the GDP values in the literature, rather than the fixed asset data. The GDP data used in the literature, as in this paper, are supposedly the official data without manipulations beyond price adjustments. To defend the fixed asset series in the literature one would have to argue that the official GDP data are wrong plus the fixed asset series derived in this paper are wrong, and that the two wrongs in the case of the fixed asset series derived in this paper combine to yield a trend that looks right. 